\title{
Research on Longitudinal Collapse Mode and Control of the Continuous Bridge under Strong Seismic Excitations
}

\author{
Yale Li ${ }^{1} \mathbb{D}$, Zhouhong Zong ${ }^{2, *}$, Bingwen Yang ${ }^{3}$, Yuanzheng Lin ${ }^{2}$ and Jin Lin ${ }^{2}$ \\ 1 Department of Building Engineering, Jiangsu Open University, Nanjing 210036, China; liyl@jsou.cn \\ 2 Department of Civil Engineering, Southeast University, Nanjing 210096, China; linyz@seu.edu.cn (Y.L.); \\ 230198121@seu.edu.cn (J.L.) \\ 3 Department of Road, Bridge, Port and Navigation Engineering, Nanjing Vocational Institute of \\ Transport Technology, Nanjing 211188, China; ybw@njitt.edu.cn \\ * Correspondence: zongzh@seu.edu.cn
}

Received: 18 July 2020; Accepted: 21 August 2020; Published: 1 September 2020

Featured Application: The collapse control methods discussed in this paper provide evidence for the anti-collapse design of multi-span continuous girder bridges. In particular, it enhances the understanding of suitable collapse control methods.

\begin{abstract}
Bridge collapse events are common in major earthquakes around the world, among which continuous girder bridges are the most involved. In order to explore the collapse mechanism of a continuous girder bridge in an earthquake, the collapse mode of a two-span continuous girder bridge specimen which had been studied by the shaking table test was analyzed. Then, on the basis of the conventional plate rubber bearing system, the collapse control strategies which were high damping rubber bearing, fluid viscous damper, lock-up clutch control methods were discussed. It is found that high damping rubber bearing can delay the collapse time but the collapse mode remains the same; lock-up clutch has the best displacement control effect for the superstructure, but its energy consumption performance is not as good as that of a fluid viscous damper; high damping rubber bearing is quite suitable for protecting the substructure under short-period ground motion to avoid the bridge collapse caused by the failure of piers; fluid viscous damper and lock-up clutch are suitable for protecting the superstructure under long ground seismic motion to avoid the bridge non-use resulted from girder lowering; three collapse control methods can improve the anti-collapse ability of the bridge specimen, although no matter which control method is used, the bridge specimen may still collapse under strong earthquakes, but the target of postponing collapse time can be realized by means of various effective control methods.
\end{abstract}

Keywords: reinforced concrete continuous girder bridge; collapse mode; collapse control; high damping rubber (HDR) bearing; fluid viscous damper (FVD); lock-up clutch(LUC)

\section{Introduction}

Seismic damage to bridges can be divided into two categories, one is damage caused by foundation failure [1], the other is damage caused by the strong vibration of bridges [2]. The former is difficult to resist through man-made structures and should if possible be avoided by site selection. The latter is caused by external ground motion intensity, the defects of internal structure design [3], and conformation and construction methods. We cannot predict the intensity of ground motion, so it is the mission of our structural engineers to design structures that are insensitive to ground motion. In order to design a structure that has little response to general ground motion and large seismic response under a strong 
earthquake but will not collapse or lose the structural function, it is necessary to study the collapse mechanism and failure mode of various types of bridge structures.

More attention is paid to the complex bridges or long-span bridges, and there are many aseismic measures. In contrast, the earthquake-resistant measures of small and medium-span bridges are relatively simple. Continuous girder bridges, which often use conformation design for its aseismic design, is a common bridge form of small and medium span bridges in highway and urban roads. Once the structure of a continuous girder bridge is damaged under a strong earthquake, the pier, as a ductile member, is most likely to be damaged. Therefore, it is usually necessary to strengthen the pier column after the earthquake [4-8]. When the pier damage is serious, it will also cause the structure collapse and cannot wait for the pier column reinforcement. At present, there are many cases of seismic damage of this kind of bridge in each major earthquake at home and abroad $[9,10]$. The reason is closely related to insufficient anti-collapse design methods.

The essence of an anti-collapse design is to choose a reasonable collapse control strategy to control the collapse mode of the bridge structure and delay the collapse time of the structure. The structure of a continuous beam bridge is relatively simple, and passive control methods are often used, such as bearing isolation, energy dissipation and shock absorption, and a restraint device. Isolation bearings include steel bearings and rubber bearings. Steel isolation bearings contain the friction pendulum bearing [11] and the spherical bearing [12]. Rubber bearings embody the lead rubber bearing [13], the high damping rubber bearing [14,15], and the slide rubber bearing [16]. Shock absorption devices are mainly dampers, which can be divided into two types: deformation energy dissipation and velocity energy dissipation. The metal damper [17-19] is representative of the former, and the viscous fluid damper [20] is related to the speed of motion, which is the representative of the latter. Restraint devices include anti-fall beam devices such as block, shear tenon, and lock-up devices [21,22].

Many pieces of research on bridge collapse are currently aimed at a bridge with actual earthquake damage. The collapse mechanism is revealed by analyzing the earthquake damage phenomenon, or the collapse course is inversed by numerical analysis. Anderson et al. [23] presented failure cases of concrete bridges during the Kobe earthquake and discussed their probable causes. Mylonakis et al. [24] analyzed the collapse of an 18-span (total length $630 \mathrm{~m}$ ) Route 3 elevated highway bridge during the 1995 Kobe earthquake by DRAIN-2DX software and revealed a quadruple detrimental role of soil. Hsu et al. [25] reported bridge damage in the Chi-Chi earthquake and analyzed the cause of damage. Li et al. [26] investigated girder bridges on National Highway 213 and the Doujiangyan-Wenchuan expressway after the Wenchuan earthquake and explained the collapse mode of the Baihua Bridge. Hu et al. [27] analyzed the collapse course of the Gaoyuan bridge in the Wenchuan earthquake based on the LS-DYNA program. Lee et al. [28] simulated the collapse process of the Matsurube Bridge which collapsed in the 2008 Japan Iwate-Miyagi inland earthquake due to strong ground excitations and the sliding of the rock mass beneath the bridge by FE model.

Besides, some researchers carried out a seismic analysis for new complex bridges. The collapse mode is predicted by a numerical model or investigated by the shaking table test, mainly for the arch bridge [29,30], cable-stayed bridge [31-33], skew bridge [34], and other special-shaped bridges [35]. However, the collapse control strategy is rarely studied from the point of view of control methods and there are few pieces of research on the common continuous girder bridge, so it is necessary to study the collapse control method of the conventional continuous girder bridge.

Due to the large number and relatively low cost of continuous girder bridges, many continuous girder bridges do not even carry out seismic isolation design. If the collapse design of many continuous girder bridges is to be carried out, the cost of its control device should not be too high. The simplest idea is to select a suitable collapse control method among the commonly used passive control methods. Rubber bearings, viscous fluid dampers, and restraint devices are taken into account. In this paper, a two-span continuous girder bridge model with a 1:3 scale, which has been studied by the shaking table test, is the study object. The collapse control effects of three different control methods which 
are high damping rubber (HDR) bearing, fluid viscous damper (FVD), and lock-up clutch (LUC), are analyzed in order to provide the basis for the anti-collapse design of continuous girder bridges.

\section{Analysis Method of Collapse Failure}

In the finite element analysis, the actual structure is discretized into a discrete structure formed by a finite number of nodes, and the equilibrium equation of the force shown in Equation (1) is established.

$$
f_{I}+f_{D}+f_{S}-P=0
$$

where $f_{I}$ is inertia force, $f_{D}$ is damping force, $f_{S}$ is elastic force, $P$ is the external force.

Then the numerical solution of the equation is carried out:

$$
[M]\{\ddot{x}\}+[C]\{\dot{x}\}+[K]\{x\}=\{P\}
$$

There are two kinds of solving methods: the implicit integral method and the explicit integral method. In general, the displacement $\{x\}$, velocity $\{\dot{x}\}$, and acceleration $\{\ddot{x}\}$ of $t_{i+1}$ in Equation (2) are obtained by the implicit integration method. However, the implicit integral method must invert the stiffness matrix $[\mathrm{K}]$ to solve the dynamic equation (Equation (2)). This methodology may result in a non-iterative non-convergence for nonlinear solutions. When the calculation does not converge out of iteration in the nonlinear dynamic analysis of large displacement, it may be caused by the unsuitable calculation parameters or the failure of the structure, so it is difficult to judge whether the structure collapses or not. Therefore, the explicit integration method has attracted people's attention.

The equation of motion of a multi-particle system at $t$ time based on the display integral method [36] is as follows:

$$
M \cdot a(t)=P(t)-F(t)+H(t)
$$

where $M$ is the mass diagonal matrix, $a(t), P(t), F(t), H(t)$ is the node acceleration vector, external force (including physical force) vector, equivalent nodal force vector and hourglass viscous damping force vector at time $t$.

Then at time $t_{\mathrm{i}}$ :

$$
a_{i}=M^{-1}\left(P_{i}-F_{i}+H_{i}\right)
$$

$P_{i}$ and $F_{i}$ in the right term are functions of $u_{i}$, from which the $a_{\mathrm{i}}$ can be obtained. Because the analytical mass matrix $M$ is the diagonal matrix, it is not needed to solve the simultaneous equations and the inverse stiffness matrix to acquire the acceleration $a_{i}$ at $t_{\mathrm{i}}$ time, so there is no convergence problem.

Assume that $t_{i+1 / 2}$ and time increment $\Delta t_{i+1 / 2}$ are:

$$
\begin{aligned}
& t_{i+1 / 2}=\frac{t_{i}+t_{i+1}}{2} \\
& \Delta t_{i+1 / 2}=t_{i+1}-t_{i}
\end{aligned}
$$

Based on the central difference method, the acceleration at $t_{i}$ time can be derived $a_{i}=\frac{v_{i+1 / 2}-v_{i-1 / 2}}{\Delta t_{i}}$, thus:

$$
\begin{gathered}
v_{i+1 / 2}=v_{i-1 / 2}+a_{i} \Delta t_{i} \\
u_{i+1}=u_{i}+v_{i+1 / 2} \Delta t_{i+1 / 2} \\
\varepsilon_{i+1}=B u_{i+1} \\
\sigma_{i+1}=E \varepsilon_{i+1}
\end{gathered}
$$

when Equations (6) and (7) are brought into Equation (8), $u_{i+1}$ can be calculated from the displacement $u_{i}$ at $t_{i}$ time. Then bring $u_{i+1}$ into the geometric equation and physical equation (see Equations (9) and (10), $B$ is strain matrix) to obtain the strain and stress at $t_{i+1}$ time, and bring $u_{i+1}$ and $t_{i+1}$ into 
Equation (3) to obtain $a_{i+1}$, therefore, calculations can continue to iterate through the loop. As long as the calculation time step is not exceeded, the calculation stability can be guaranteed.

In summary, the explicit integral method is more suitable for the collapse analysis of structures with large displacement and large deformation than the implicit integral method [37]. The LS-DYNA software is a non-linear dynamic finite element simulation analysis software with an explicit integral method as the main method and implicit analysis method as the auxiliary, which is very suitable for large-displacement and large-deformation structural collapse calculation. Therefore the structural collapse simulation and analysis of two-span continuous girder bridge specimen are carried out based on this platform.

\section{Collapse Control Mechanism}

The essence of structural collapse control is to delay the time of collapse under the earthquake by means of various effective control methods. The control methods are derived from the structural vibration control methods, which are mainly divided into passive control, active control, and semi-active control and mixed control which are developed on them. The passive control method is to change the inherent properties (stiffness, mass, damping) of the controlled structure by placing a subsidiary structure on the structure, in order to reduce the vibration deformation of the controlled structure under external load. It can be understood in the kinetic equation as changing the left end term of Equation (2) to achieve the effect of controlling vibration. Active control means that the external energy control actuator provides the control forces acting on the structure. That is, applying an external load to change the right end load term of Equation (2), to reduce or offset the vibration deformation influence of the earthquake on the structure.

Passive control has the characteristics of simple structure, low cost, easy maintenance, and no external energy input [38], while active control needs external energy, and the technology is complex [39], with a high cost and poor reliability. Therefore, the passive control method is more feasible for the continuous girder bridge [40] discussed in this paper. The main design ideas of passive control are vibration isolation, energy dissipation, and energy transfer. This paper intends to use HDR bearing isolation for isolation collapse control, FVD for energy dissipation collapse control, and LUC for transfer collapse control.

\subsection{HDR Bearing Isolation and Collapse Control}

The HDR bearing is a kind of seismic isolation rubber bearing in which the damping of the material is increased by improving the formula of the rubber on the basis of the conventional rubber bearing, so as to exert the seismic-absorbing effect of the isolation rubber bearing. It combines vertical bearing capacity, horizontal restoring force, and damping. The initial elastic stiffness can have a braking effect on wind load, which is similar to plate rubber bearing, and the bearing plays the role of damping and energy dissipation when large displacement occurs. On the one hand, it maintains the good mechanical properties of plate rubber bearing, and it has high damping rubber viscosity and high damping (its damping ratio can be about 0.15 ), so it can absorb seismic energy and reduce seismic response in an earthquake. Based on its good isolation characteristics, it can be further designed to control the collapse of the structure. The earthquake damage of the bridge can be effectively reduced by utilizing the comprehensive performance of the HDR bearing [41]. In addition, the cost of HDR bearings is not high, the environmental impact is small, and the damping is less influenced by the temperature [42]. Therefore, HDR bearing research is also ongoing in recent years.

\subsection{Fluid Viscous Damper Shock Absorption and Collapse Control}

A fluid viscous damper is a kind of damper. Its working principle is to drive the piston to reciprocate in the cylinder by the piston rod, thus liquid (silicone oil) flows through a specially shaped piston head and provides different damping forces by different flow rates of liquid. Figure 1 shows the specific construction. Through the energy consumption of the damper, the input energy by the seismic 
wave is absorbed, and the damage of the bridge structure is reduced by the damper so that the risk of the structure collapse is reduced. Therefore, the collapse control of the damper is mainly related to its own energy-absorption mechanism and capacity. The energy consumption principle of the FVD is described below.

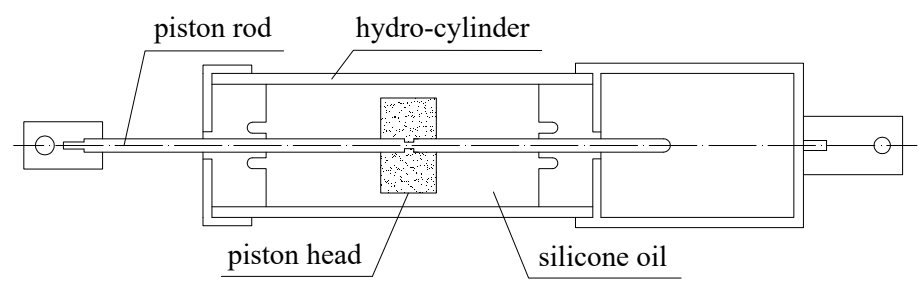

Figure 1. Schematic Diagram of Fluid Viscous Damper.

The FVD is a velocity-dependent damper whose damping force can be expressed as:

$$
F=C v^{\alpha}
$$

where $C$ is the damping coefficient, $v$ is the velocity, and $\alpha$ is the velocity index.

When the seismic input is certain, then $v$ is the definite value, so the damping force is related to the values of $C$ and $\alpha$. When $\alpha$ is certain, the larger the $C$ is, the greater the $F$ is. When $C$ is certain, $F$ varies with the velocity index $\alpha$.

When $v$ is greater than $1 \mathrm{~m} / \mathrm{s}$, the curve of $\mathrm{F}$ with $\alpha$ greater than 1 rises faster than that with $\alpha$ less than 1 , and the change speed of curve $\mathrm{F}$ with $\alpha$ equal to 1 is between the two. When the speed is less than $1 \mathrm{~m} / \mathrm{s}$, the curve $F$ with $\alpha$ less than 1 is faster than that with $\alpha$ more than 1 . If $v$ is less than $1 \mathrm{~m} / \mathrm{s}$, the law is the opposite. See Figure 2 for details.

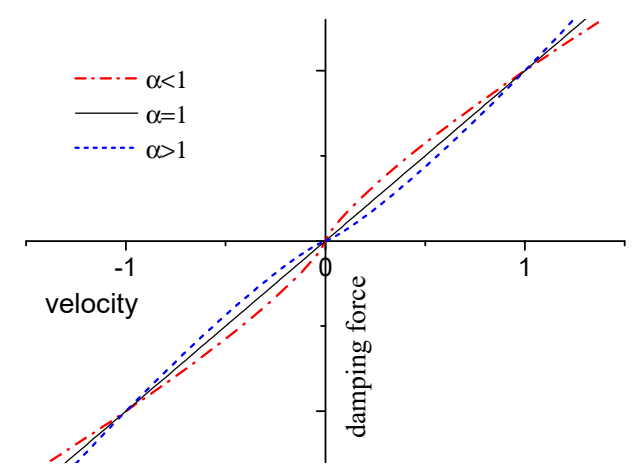

Figure 2. Damping Force and Velocity Curve with different Velocity Indices.

The increasing speed of the damping force $\mathrm{F}$ is not the most important factor of the velocity index $\alpha$. The change of $\alpha$ directly influences the energy consumption level of the damper in the case of assumed $v$ and $\alpha$. Assuming that the motion of the damper is the simplest sinusoidal curve $u=u_{0} \sin \omega_{0} t$, thus the damper completes one cycle of the displacement-consumption energy $W_{d}$ is

$$
W_{d}=\int_{0}^{T} F \dot{u} d t
$$

where $T, u_{0}, \omega, F$ are sine wave vibration period $\left(2 \pi / \omega_{0}\right)$, amplitude, circular frequency, and output force of the damper, respectively. 
According to Equation (12), the integral can be obtained:

$$
W_{d}=4 \cdot 2^{\alpha} \cdot \frac{\Gamma^{2}\left(1+\frac{\alpha}{2}\right)}{\Gamma(2+\alpha)} \cdot C \cdot u_{0}^{1+\alpha} \omega_{0}^{\alpha}
$$

where $\Gamma$ is the Gamma function.

The maximum $F_{\max }$ of the output force of the damper is $C u_{0}^{\alpha} \omega_{0}^{\alpha}$, so the Equation (13) can be simplified as follows:

$$
W_{d}=4 \cdot 2^{\alpha} \cdot \frac{\Gamma^{2}\left(1+\frac{\alpha}{2}\right)}{\Gamma(2+\alpha)} \cdot F_{\max } \cdot u_{0}
$$

If we assume $\psi=4 \cdot 2^{\alpha} \cdot \frac{\Gamma^{2}\left(1+\frac{\alpha}{2}\right)}{\Gamma(2+\alpha)}$, Equation (14) can be abbreviated as:

$$
W_{d}=\psi \cdot F_{\max } \cdot u_{0}
$$

If the maximum output $F_{\max }$ and the maximum displacement $\mathrm{u}_{0}$ of the damper are fixed design parameters, the energy consumption level is linearly related to the parameter $\psi$. The value of $\psi$ is essentially the value of the velocity index $\alpha$, and the smaller $\alpha$ is, the stronger the energy dissipation capacity is. For example, when $\alpha=0.4, \psi=3.58$, while $\alpha=0.8, \psi=3.27$. However, when the value of $\alpha$ is close to $0, v^{\alpha}$ is close to 1 and the damping force $F$ is basically only related to $C$, which will lose the basic characteristics of the velocity correlation of viscous dampers. This is contrary to the original intention of the design, so the value of velocity index $\alpha$ is not needed to be too small, usually between 0.2 and 1.

The velocity index of the FVD used for the anti-seismic designed bridge has not been unified, and the appropriate $\alpha$ can only be analyzed according to the specific conditions. When $\alpha$ is 1 , the damper is linear, and when $\alpha$ is less than 1 , it is nonlinear. The nonlinear degree of the damper is higher so that the energy consumption efficiency is higher on the condition that $\alpha$ is smaller.

In practical engineering cases, it has been found that the velocity index of dampers with the best isolation effect is not the minimum in all schemes. Therefore, the nonlinear degree of the damper can not determine the efficiency of seismic isolation. The evaluation of the design scheme of the FVD needs to be judged by combining the seismic comprehensive response of the whole structure of the bridge. Based on the FVD with better energy dissipation and shock absorption performance, it is possible to control the collapse of the bridge. The reasonable arrangement of dampers can be an anti-collapse design.

\subsection{Shock Transmission Unit and Collapse Control}

The shock transmission unit is a temporary or permanent connection device that is set up in some parts of the bridge in order to prevent excessive structural displacement. It is a speed-dependent constraint device, called a lock-up device. It can be regarded as a simple velocity switch. When the velocity is greater than the starting value (e.g., under seismic action, braking force, wind load), the device works and becomes a rigid connecting rod. If the velocity is lower than the starting speed (e.g., under temperature load and normal live load), the device does not play a role, so the response of the bridge under load is not affected by the shock transmission unit. Though the shock transmission unit is modified from the viscous damper, it does not provide energy consumption. The working principle of the invention is to increase the internal constraint of the bridge through the locking function of the connecting rod so that the action of the seismic wave can be more uniformly distributed to the various components and the structural potential is fully exerted. In this way, the stress concentration on the key components can be avoided, which can cause serious damage and even cause the whole collapse. 
The output of the lock-up device can be expressed by Equation (15):

$$
F= \begin{cases}0 & V \leq V_{0} \\ 0 \rightarrow F_{\max } & V>V_{0}\end{cases}
$$

where $V_{0}$ is the starting velocity, $F_{\max }$ is the peak locking force.

\section{Case Study}

\subsection{Bridge Specimen Background}

A highway reinforced concrete continuous T-girder bridge with $4 \times 20 \mathrm{~m}$ spans was taken as the prototype bridge. The scale of the bridge was reduced considering the comprehensive factors such as test conditions and reliability of test results. Finally, a two-span continuous girder bridge specimen with a geometric similarity ratio of $1: 3$ was made and tested using the shaking table array system (see Figure 3). There were two kinds of bearings: ordinary laminated rubber bearing and high damping rubber bearing, as illustrated in Figure 4 The seismic response of the bridge specimen on two supporting conditions were tested respectively [43].

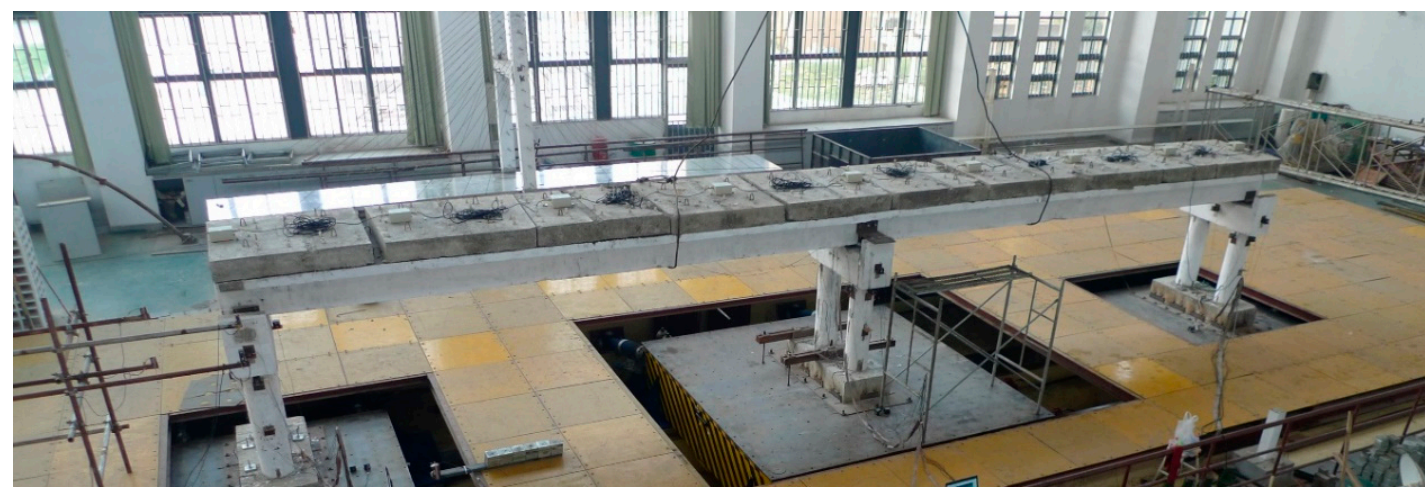

Figure 3. Continuous girder bridge specimen in shaking table test.

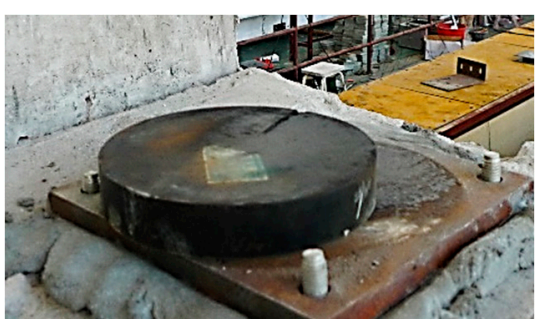

(a)

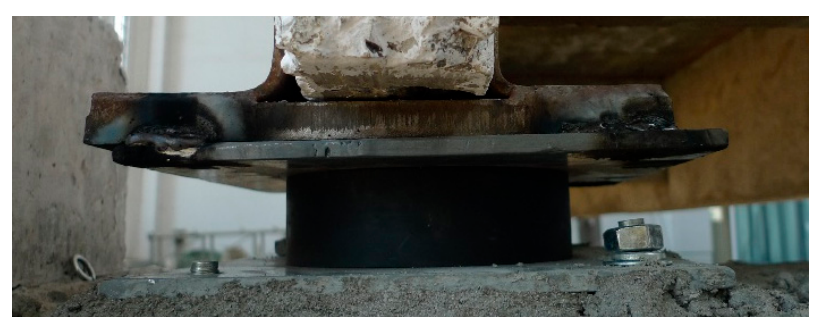

(b)

Figure 4. Bearing types: (a) laminated rubber bearing (b) high damping rubber bearing.

\subsection{Collapse Control Bridge System}

On the basis of the conventional laminated plate rubber bearing system (BC system) of the bridge specimen, three different collapse control methods are considered to fulfill collapse control design. The CHDR system, CFVD system, and CLUC system are formed. Control system 1\# is a system replacing the conventional plate rubber bearings in the basic system for HDR bearings with a total number of six. The control system 2\# involved two FVDs in the longitudinal direction between the side pier and the main girder on the basis of the basic system. The control system 3\# substitutes FVD with LUC on the basis of the control system 2\#. The layout information of bridge systems is summarized in Table 1. 
Table 1. Layout Information of Bridge Systems. BC: XXX; CHDR: XXX; CFVD: XXX; CLUC: XXX.

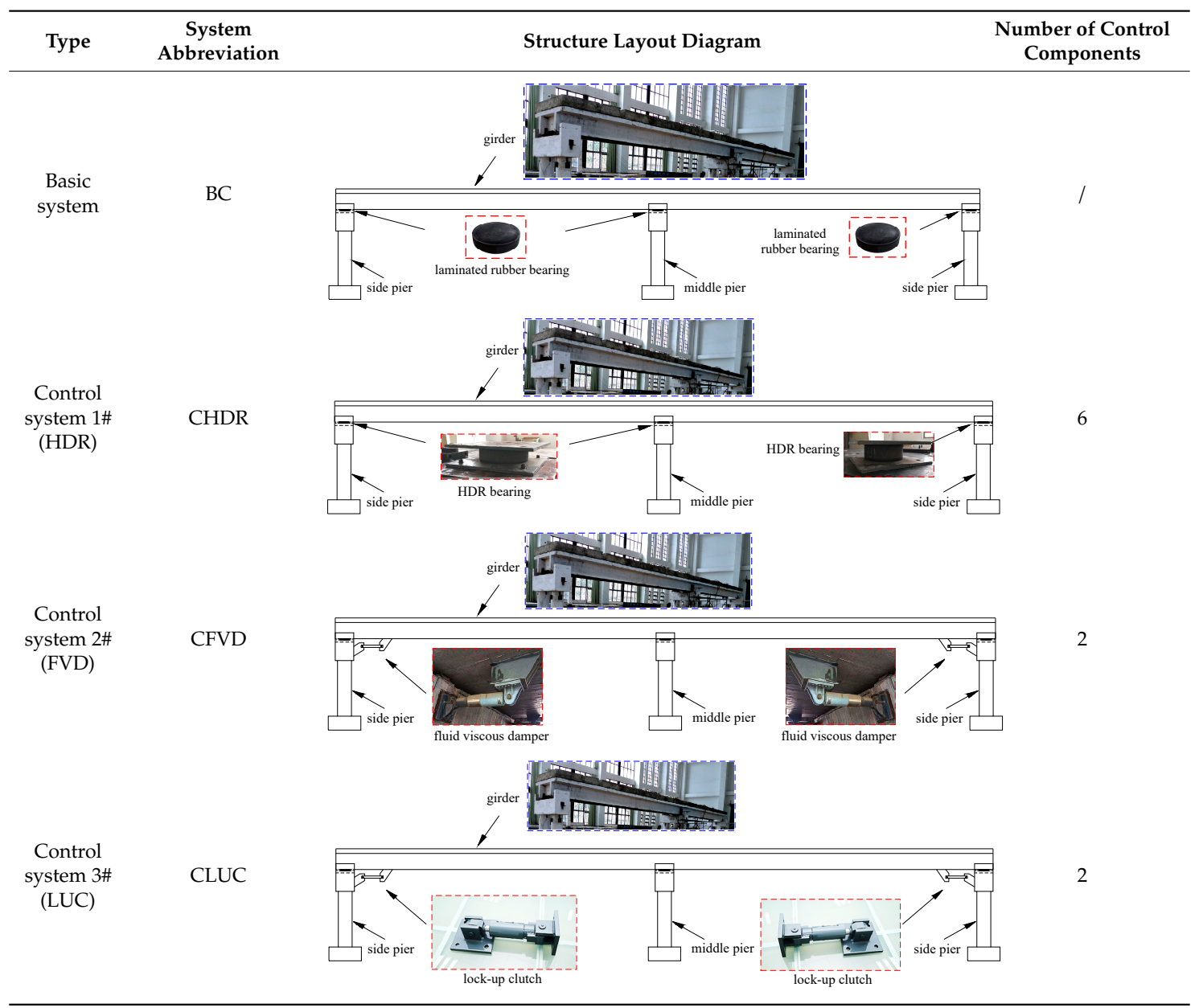

The horizontal shear stiffness of bearing, as is known to all, has a great influence on the seismic response of isolated bridges. These important parameters of conventional laminated plate rubber bearings in the $\mathrm{BC}$ system and HDR bearings in the CHDR system have been obtained from the manufacturer or measured by our bearing performance test [42]. On this basis, there may be deviation of horizontal shear stiffness caused by dynamic loading conditions such as strain rate [44]. Therefore, model updating will be done to modify the vertical and horizontal shear stiffnesses of bearings later.

\subsection{Analysis Model and Model Updating}

LS-DYNA software [36] was used to study the failure process of continuous girder bridge specimen under seismic action. The concrete was simulated by solid elements. The cube compressive strength of the concrete was $32 \mathrm{MPa}$ and uniaxial compressive strength was $23 \mathrm{MPa}$. The uniaxial tensile strength of the concrete was $2.24 \mathrm{MPa}$ while elastic modulus was $2.75 \times 10^{4} \mathrm{MPa}$. The material number of concrete was Mat_024, which was an elastoplastic material with an arbitrary stress-strain curve (see Figure 5a). If the compressive strain reached 0.0033 or the tensile stress reached $2.24 \mathrm{MPa}$, the concrete would fail. The material number of the steel bar was Mat_003, which had a bilinear kinematic hardening (see Figure $5 b$ ). $E$ and $E_{t}$ were the slopes of the bilinear stress-strain curve. Specific parameters are shown in Table 2. The connection between steel bars and concrete was simulated by common nodes, without considering the slip and fracture of steel bars. The counterweight block was specified as mass elements which were assumed to be lumped at the nodes, and each mass node was $9.3 \mathrm{~kg}$ weight. 


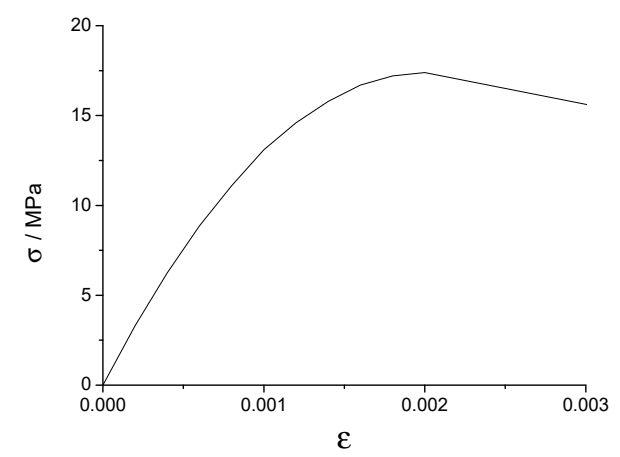

(a)

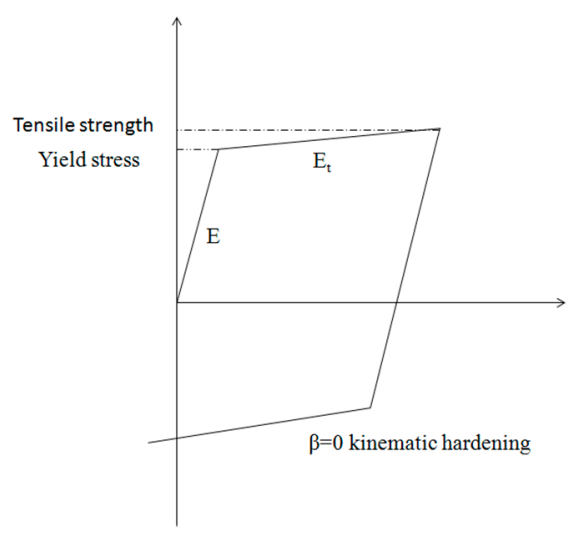

(b)

Figure 5. Constitutive relationship: (a) the concrete (b) the steel bar.

Table 2. Parameters of the specimen materials.

\begin{tabular}{|c|c|c|c|}
\hline \multicolumn{4}{|c|}{ Concrete } \\
\hline Concrete & Compressive & Elastic & Tensile \\
\hline Grade & Strength (MPa) & Modulus (MPa) & Strength $(\mathrm{MPa})$ \\
\hline 30 & 32 & $2.75 \times 10^{4}$ & 2.24 \\
\hline \multicolumn{4}{|c|}{ Steel } \\
\hline Reinforcement & Yield & Elastic & Tensile \\
\hline Diameter & Strength (MPa) & Modulus (MPa) & Strength $(\mathrm{MPa})$ \\
\hline$\varphi 10$ & 351 & $2.01 \times 10^{5}$ & 558 \\
\hline$\varphi 6.5$ & 350 & $2.04 \times 10^{5}$ & 531 \\
\hline
\end{tabular}

Discrete spring elements were chosen to model the laminated rubber bearing. The material number was MAT_S01. The longitudinal, horizontal, and vertical stiffness of the middle bearing was $955 \mathrm{kN} / \mathrm{m}, 1 \times 10^{3} \mathrm{kN} / \mathrm{m}$, and $5 \times 10^{5} \mathrm{kN} / \mathrm{m}$. The longitudinal, transverse, and vertical stiffness of the side bearing was $550 \mathrm{kN} / \mathrm{m}, 800 \mathrm{kN} / \mathrm{m}$, and $2 \times 10^{5} \mathrm{kN} / \mathrm{m}$, respectively. If the spring force exceeded the maximum shear force of the bearing, it would withdraw from working, and the cap beam slid on the top of the girder, which was simulated by the contact element with static and dynamic friction coefficients of 0.3 and 0.15 .

To model the HDR bearing, solid elements and discrete spring elements were used. The material numbers of the vertical discrete spring element and horizontal discrete spring element were MAT_S01 and MAT_S03, respectively. The vertical stiffness of the side bearing and middle bearing were $1 \times 10^{5} \mathrm{kN} / \mathrm{m}$ and $4 \times 10^{5} \mathrm{kN} / \mathrm{m}$, respectively. The horizontal constitutive relation of the HDR bearing has been tested [42] and illustrated in Figure 6. The longitudinal stiffness and transverse stiffness of the steel plate fixing the middle bent were $3 \times 10^{3} \mathrm{kN} / \mathrm{m}$ and $600 \mathrm{kN} / \mathrm{m}$, respectively. The steel plate would fail if the shear force exceeded the ultimate shear force $(40 \mathrm{kN})$. The bearing would slide when the sheer force of the support was more than the static friction. Contact simulation was used as the interaction between the pier and the girder after the bearing slid. The static and dynamic friction coefficients were 0.3 and 0.15 , respectively. Figure 7 shows the finite element model. 


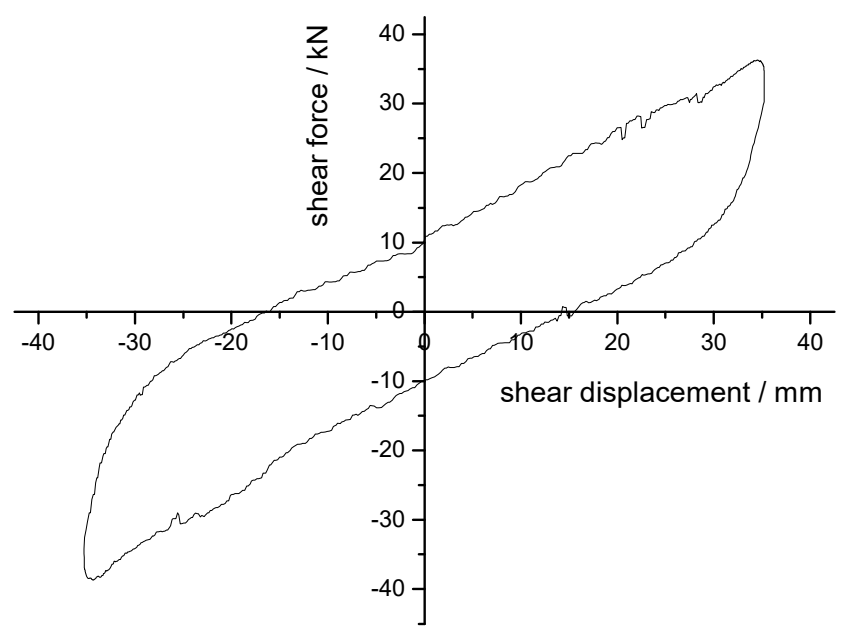

Figure 6. Constitutive relationship of the high damping rubber (HDR) bearing.

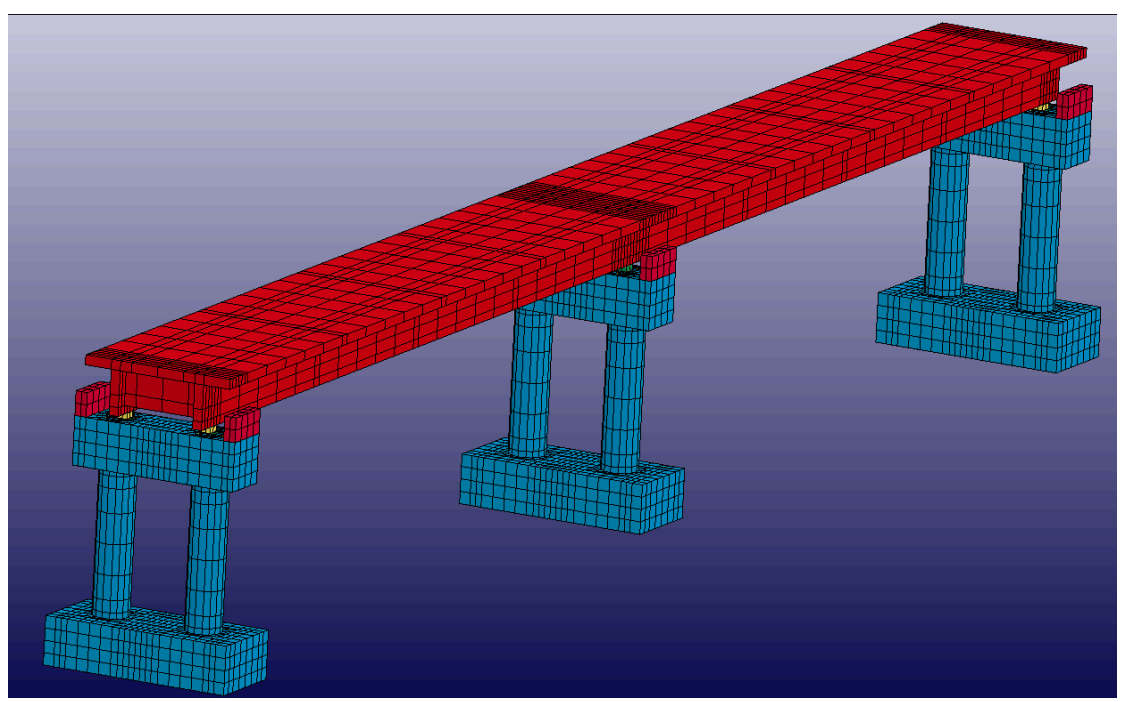

Figure 7. FEA Model.

$\mathrm{BC}$ system and CHDR system were tested in the shaking table array test and the ambient vibration test was carried out before the shaking table test. The stochastic subspace identification (SSI) method was chosen for modal parameter identification. Self-developed data analysis software called MACES was used to identify the frequency of the bridge model using the SSI method. Finally, the natural frequencies of the bridge specimens in longitudinal, transverse, and vertical directions were obtained and used for model updating. Take bridge specimens with HDR bearings (CHDR system) for example, the finite element model parameters of this system were updated based on the measured longitudinal vibration frequency [41] of the first three orders. In order to prove the effectiveness of the model modification, modal analysis was developed to acquire the longitudinal, horizontal, and vertical frequencies which were calculated frequencies in Table 2. The results of the modified finite element model agreed well with the experimental values (see Table 3), thus the finite element model could be used as a computational model for collapse analysis. 
Table 3. Natural Vibration Characteristics of the Bridge Specimen with HDR Bearings.

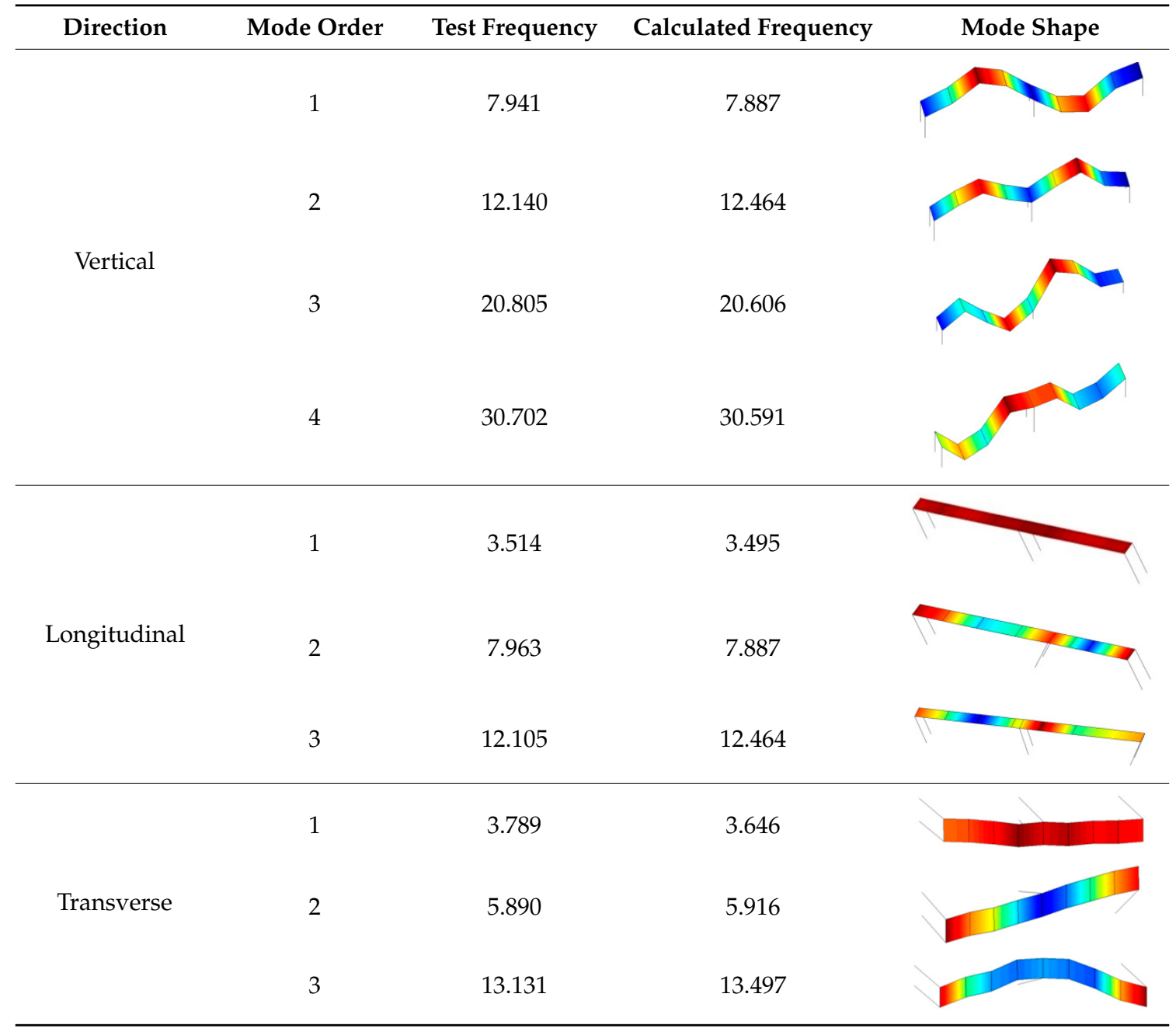

\section{Collapse Failure Analysis of the BC System}

Because the shaking table test does not study the seismic performance of the specific site, considering the duration, acceleration amplitude, and spectral composition of various seismic records, four kinds of seismic waves were tested. The Landers seismic wave, Cerro Prieto seismic wave, El Centro seismic wave, and Chi-Chi seismic wave, which represent four kinds of soil types: hard, medium-hard, medium soft, and weak, respectively.

In order to save space, only two kinds of longitudinal wave input cases in collapse analysis are analyzed below, and the original seismic wave information is shown in Table 4 . The seismic waves used in the shaking table test and the collapse analysis need to be compressed 0.408 times of the original seismic record to satisfy the similarity relationship. Longitudinal test seismic wave with peak ground acceleration (PGA) of $0.05 \mathrm{~g}$ is depicted in Figure 8. The PGA of seismic waves input in collapse analysis rose gradually from $0.1 \mathrm{~g}$ until the bridge specimen collapsed.

Table 4. Original shaking wave details.

\begin{tabular}{cccccc}
\hline Wave & Observation Station & Year & Duration/s & PGA/m· $\mathbf{s}^{\mathbf{2}}$ & Predominant Period/s \\
\hline El Centro & Imperial Valley, USGS & 1940 & 53.460 & 3.4 & 0.19 \\
Chi-Chi & TCU117 & 1999 & 89.995 & 1.2 & 0.57 \\
\hline
\end{tabular}




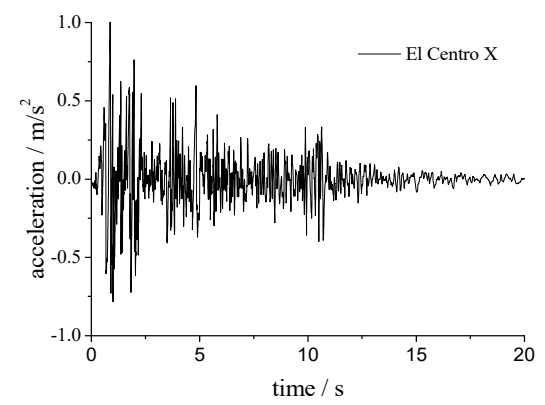

(a)

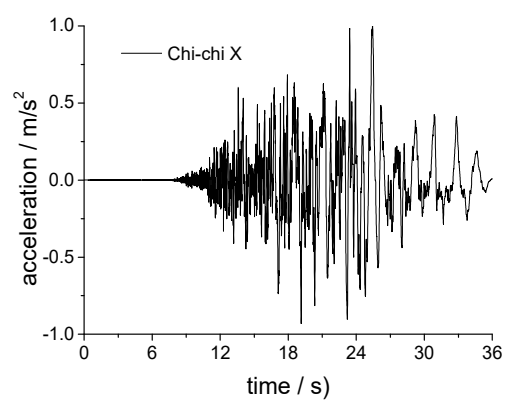

(b)

Figure 8. Longitudinal test seismic wave: (a) El Centro wave, (b) Chi-chi wave.

The bridge specimen of the BC system collapsed under the action of the El Centro wave with a longitudinal PGA of $1.2 \mathrm{~g}$. Figure 9 depicts the whole damage process from slight damage to the final collapse, which is described as follows: when $t$ was $0.81 \mathrm{~s}$, at the bottom of the middle pier the cracks started, and when $t$ was $0.84 \mathrm{~s}$, the failure at the bottom of the pier intensified and some hoops were exposed; when $t$ was $1.05 \mathrm{~s}$, the laminated rubber bearings on the middle pier failed, and the failure of the middle pier resulted in the loss of girder support and the cracking at the bottom of the girder; when $t$ was $1.13 \mathrm{~s}$, the ribs of the T beam continued to crack; finally, when $t$ was $1.44 \mathrm{~s}$, the girder was destroyed and the bridge collapsed.

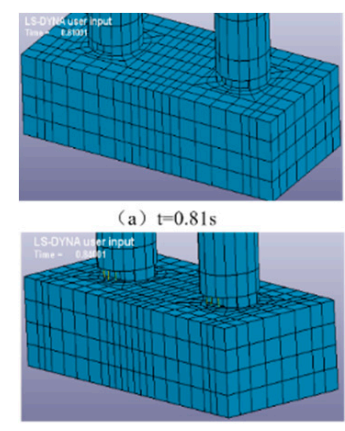

(b) $t=0.84 \mathrm{~s}$
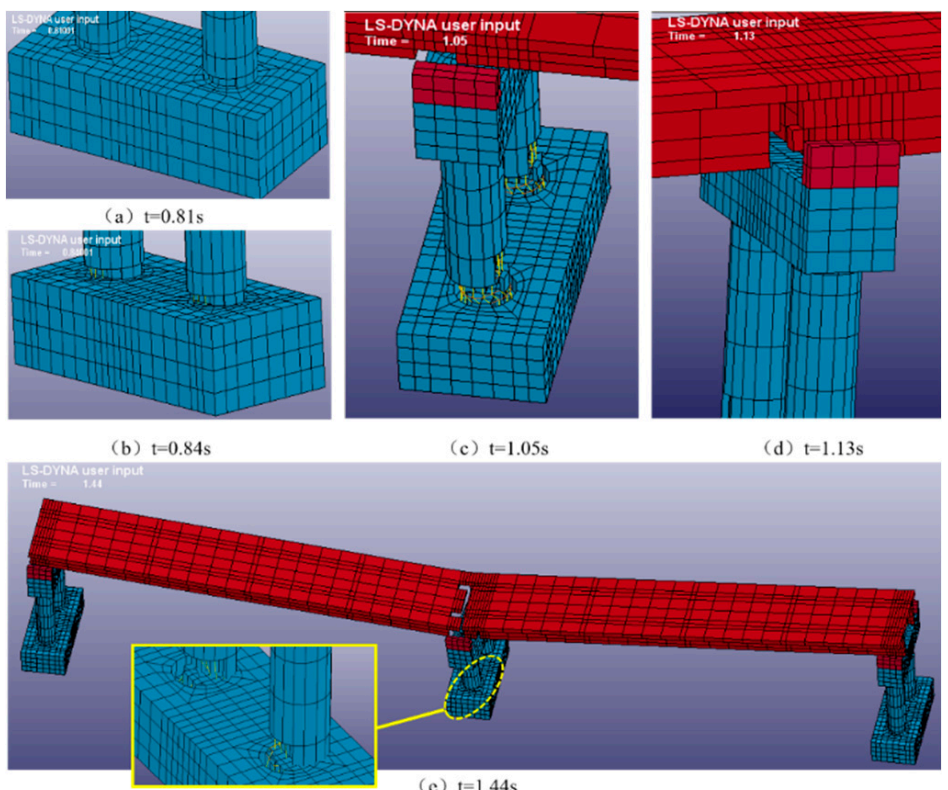

(d) $\mathrm{t}=1.13 \mathrm{~s}$ 

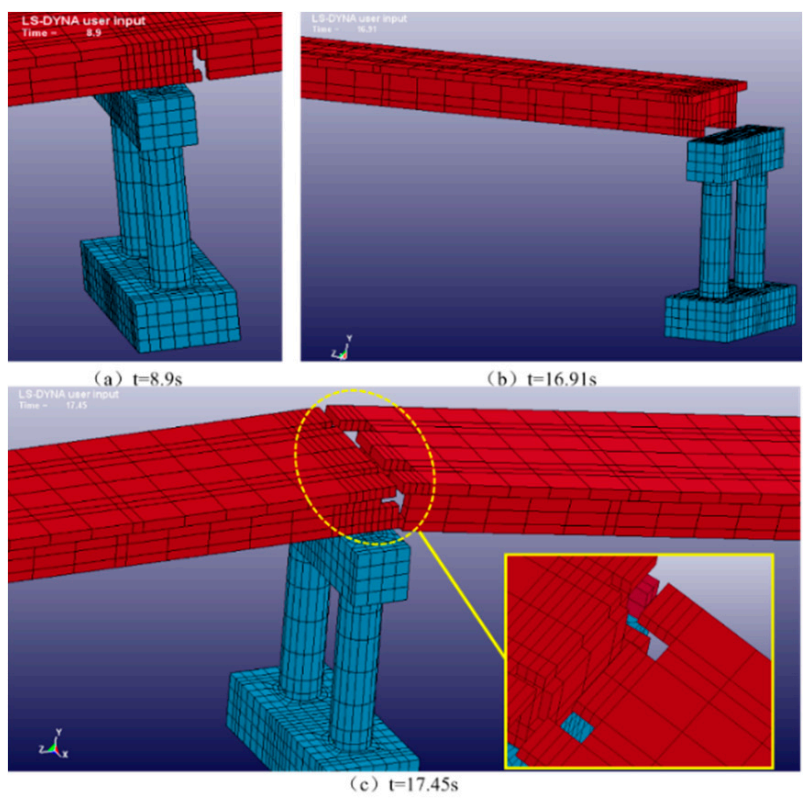

Figure 10. Longitudinal collapse mode of the bridge specimen under the Chi-chi wave.

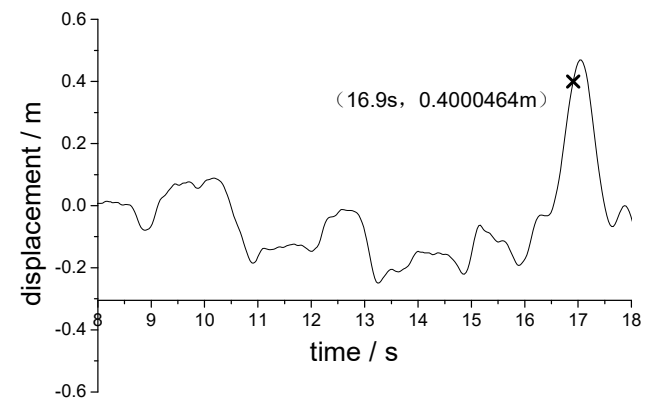

Figure 11. Relative displacement response of side pier and girder.

\section{Discussion of the Control Effects of the Collapse Control System}

\subsection{HDR Bearing Control}

Based on the modified finite element model of the CHDR system, the collapse analysis of the bridge specimen under strong earthquakes was carried out. Two typical seismic wave inputs in Table 3 were used to illustrate the collapse characteristics of the CHDR system.

There damage and destruction phenomena in the bridge specimen under the longitudinal $2.0 \mathrm{~g}$ PGA wave of El Centro is shown in Figure 12. First of all, the failure of steel plates appeared at $0.61 \mathrm{~s}$. The bottom of the concrete middle pier was crushed at $0.8 \mathrm{~s}$. When the time was $0.83 \mathrm{~s}$, the bearing on the middle pier failed and the bottom of the middle pier continued to damage. The bottom section of the middle pier completely failed and had obvious deflection at $1.15 \mathrm{~s}$ (see Figure 13). The two-span continuous girder became a simply supported girder, for the main beam lost its vertical support from the middle pier. Then cracks occurred on the bottom of the main girder near the middle bearings. When the time was $1.5 \mathrm{~s}$, the main beam in the vicinity of the middle pier was bent and vertically broken in the shape of a $\mathrm{V}$, so the bridge specimen structure collapsed completely. 


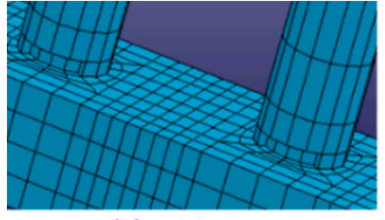

(a) $\mathrm{t}=0.8 \mathrm{~s}$

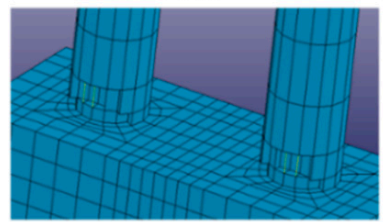

(b) $\mathrm{t}=0.83 \mathrm{~s}$

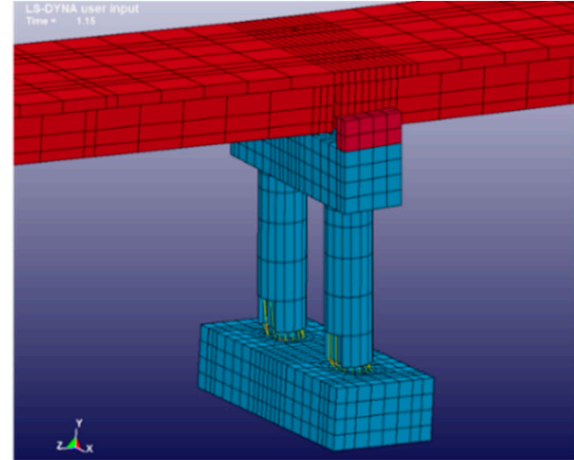

(c) $\mathrm{t}=1.15 \mathrm{~s}$

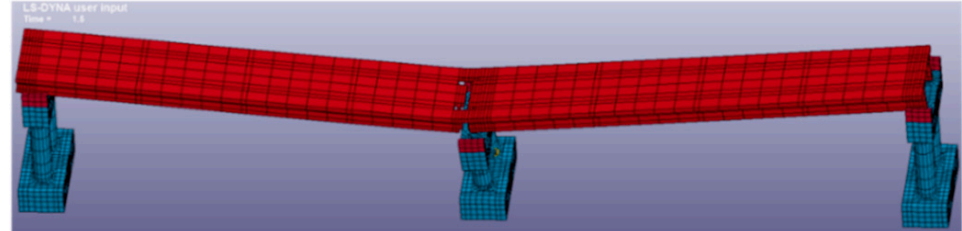

(d) $\mathrm{t}=1.5 \mathrm{~s}$

Figure 12. Longitudinal collapse mode of the CHDR system under the El Centro wave.

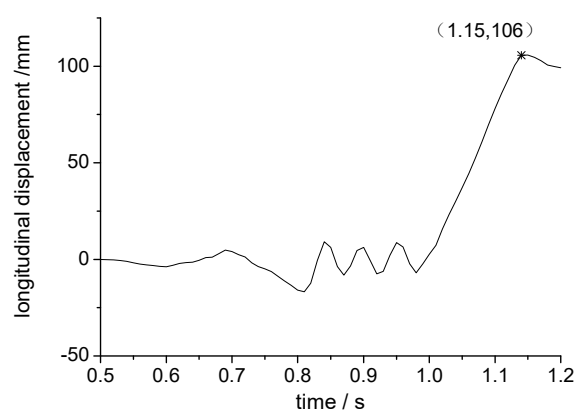

(a)

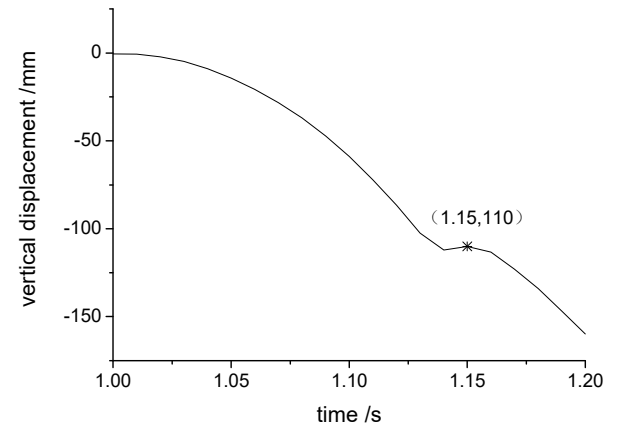

(b)

Figure 13. Displacement time history curve of the middle pier top: (a) longitudinal (b) vertical.

The CHDR system specimen collapsed under the Chi-chi seismic wave action in the longitudinal direction of $1.6 \mathrm{~g}$ PGA, as shown in Figure 14. The failure of the steel plate occurred at $2.98 \mathrm{~s}$. The girder and the middle pier were relatively sliding at $16.2 \mathrm{~s}$ after the middle bearings were destroyed. When the time was $16.82 \mathrm{~s}$, the bottom of the concrete middle pier was broken, and the longitudinal reinforcement and stirrup could be seen at $16.9 \mathrm{~s}$. Due to the large seismic displacement response, left side pier was separated from the main girder at $17.52 \mathrm{~s}$, and the relative longitudinal displacement of the pier and the girder reached the peak value at $24.88 \mathrm{~s}$ (see Figure 15). When the time was $33.541 \mathrm{~s}$, the main girder bounced and lost the support of the bent (see Figures 14e and 16), so the girder became a double cantilever beam instantaneously. The increasing hogging moment of the main girder in the vicinity of the middle pier leads to cracking of the girder (see Figure 14e). The main girder increasingly cracked when the time was $33.821 \mathrm{~s}$ and disconnected from the center at $34.001 \mathrm{~s}$, thus lowering of the main girder in a down V shape happened, as demonstrated in Figures 14g and 16. 


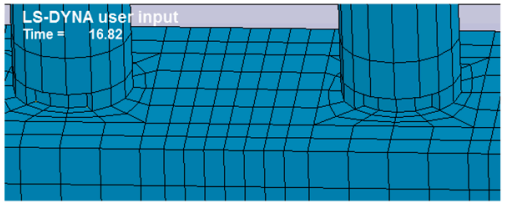

(a) $\mathrm{t}=16.82 \mathrm{~s}$

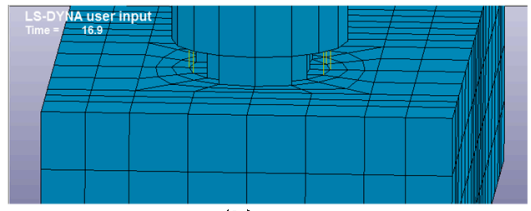

(b) $t=16.9 \mathrm{~s}$

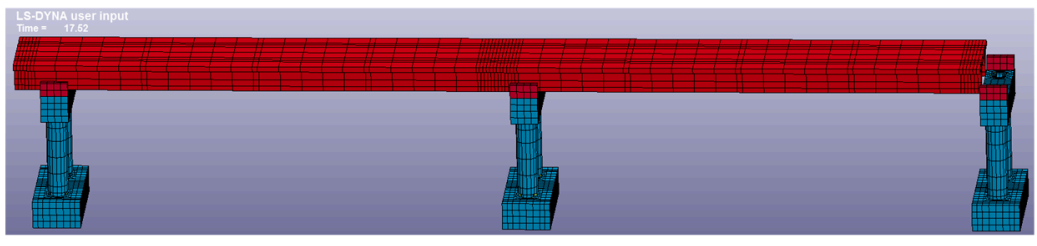

(c) $\mathrm{t}=17.52 \mathrm{~s}$

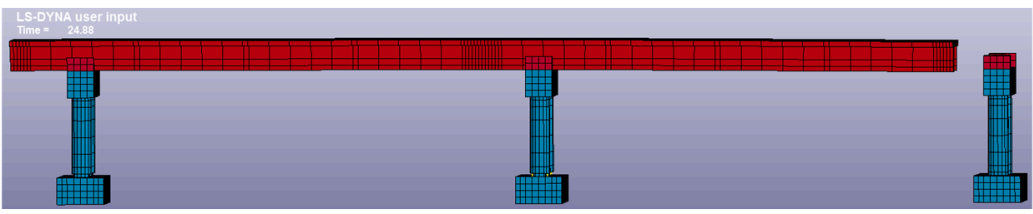

(d) $t=24.88 \mathrm{~s}$

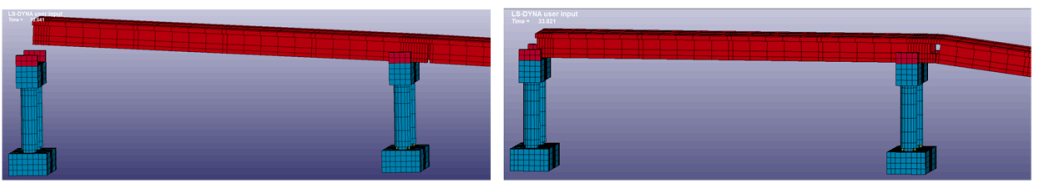

(e) $\mathrm{t}=33.541 \mathrm{~s}$

(f) $\mathrm{t}=\mathbf{3 3} .821 \mathrm{~s}$

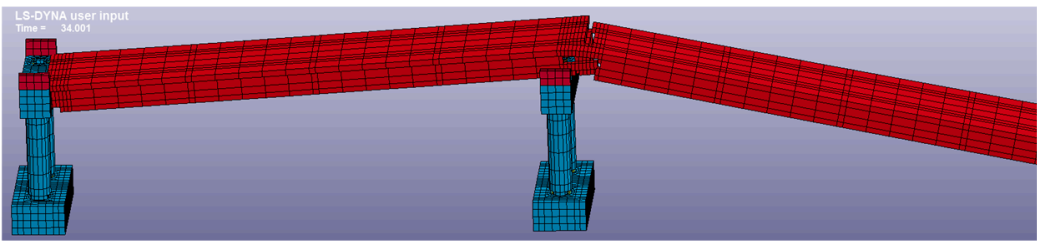

(g) $\mathrm{t}=34.001 \mathrm{~s}$

Figure 14. Longitudinal collapse mode of the CHDR system under the Chi-chi wave.

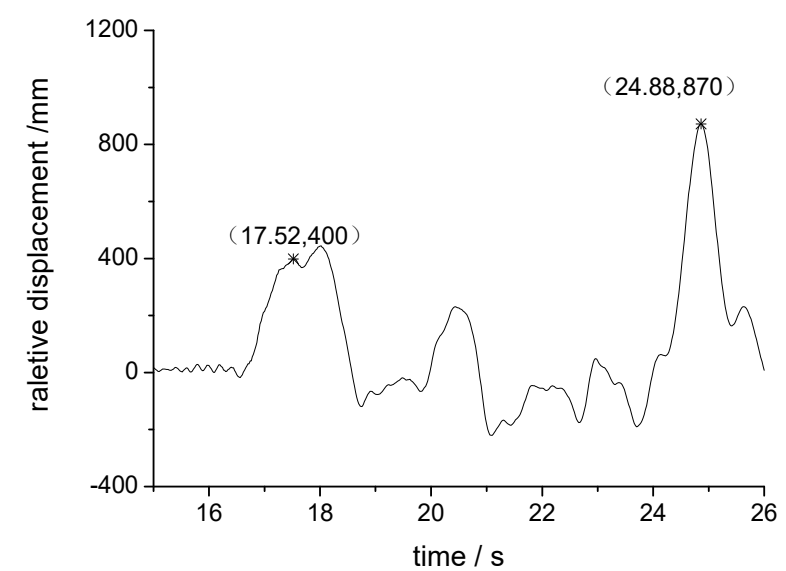

Figure 15. Time history curve of relative longitudinal displacement of the pier and the girder. 


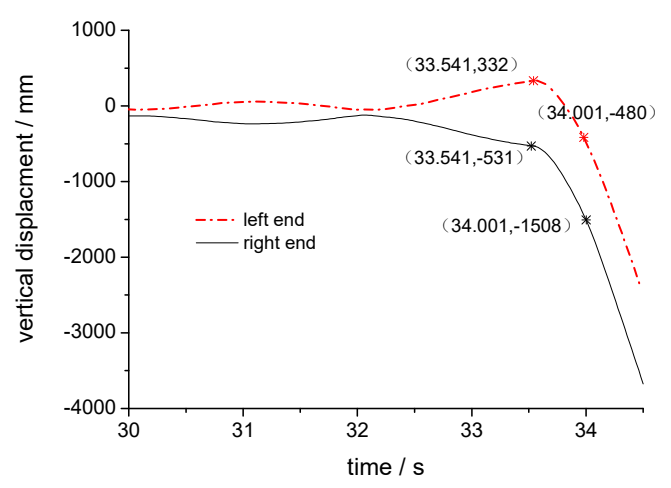

Figure 16. Time history curve of vertical displacement of the end of the main girder.

\subsection{Fluid Viscous Damper Control}

\subsubsection{Parameter Setting}

Due to the differences in bridge type, site, control target, and so on, the design parameters of the FVD used in each engineering case are different. The main design parameters are damping coefficient $\mathrm{C}$ and velocity index $\alpha$. According to the characteristics of the object studied in this paper, it is determined that the optimal range of damper parameters are as follows: $C$ increases from $1 \mathrm{kN} \cdot(\mathrm{s} / \mathrm{m})^{\alpha}$ to $12 \mathrm{kN} \cdot(\mathrm{s} / \mathrm{m})^{\alpha}$, and $\alpha$ varies from 0.2 to 1 . Thus, 42 parameter schemes are obtained. After that, the isolation effect of the CHDR system is taken as the optimization objective. In order to make the CFVD system comparable with the existing CHDR system and have certain advantages, the relative displacement between the side pier and the girder and the bending moment at the bottom of the middle pier should be smaller than those in the CHDR system. Eight of 42 schemes meet those conditions, so the scope of schemes is reduced to 8 . Therefore, the range of design parameters is reduced as $\mathrm{C}$ ranging from $8 \sim 12 \mathrm{kN} \cdot(\mathrm{s} / \mathrm{m})^{\alpha}$ and $\alpha$ between 0.2 and 0.4 . The control of the structure by the FVD is reflected in the control of force and deformation. Considering the characteristics of seismic damage and collapse failure of the continuous girder bridge, displacement control is important. Sometimes the large displacement response of the substructure leads to serious consequences of girder lowering, so the damping coefficient $C$ should not be too small. In the condition of the same damping coefficient $C$, the smaller the speed index $\alpha$, the better the effect of controlling the bending moment of the middle pier. Then, from the consideration of economy and non-linearity, the final compromised design parameters of the FVD are as follows: $C$ is $10 \mathrm{kN} \cdot(\mathrm{s} / \mathrm{m})^{0.4}$ and $\alpha$ is equal to 0.4 . These parameters were used to set the damping material in the FEA model for simulation of the FVD.

\subsubsection{Analysis of Isolation and Collapse Control Effect of the FVD}

\section{(1) Isolation effect}

After the BC system is replaced with the control system, the seismic response of the bridge specimen is weakened. In order to compare the collapse control effect of different control systems in the later stage, the damping effect of the CFVD system and CLUC system under conventional ground motion is needed to be close to that of the CHDR system.

Taking the El Centro wave case with longitudinal PGA of $0.4 \mathrm{~g}$ as an example, the peak relative displacement between the side pier and the girder in the CHDR system was reduced from $12.3 \mathrm{~mm}$ of the BC system to $10 \mathrm{~mm}$, which showed an isolation rate of $18.7 \%$. In the CFVD system, the peak relative displacement between the side pier and the girder was reduced from the initial $12.3 \mathrm{~mm}$ to $9.1 \mathrm{~mm}$, and the isolation rate is $26 \%$, as shown in Figure 17 and Table 5. The displacement control of the damping scheme was slightly better than that of the HDR isolation scheme, which was due to the fact that the actual energy consumption of the FVD is larger than that of the HDR, as shown in Figure 18. In addition, the damping force influence of the FVD on the middle pier is almost the same 
as that of the HDR. Therefore, the response of the CFVD system is comparable to that of the CHDR system. In summary, the design parameters of the FVD are quite suitable for control effect analysis.

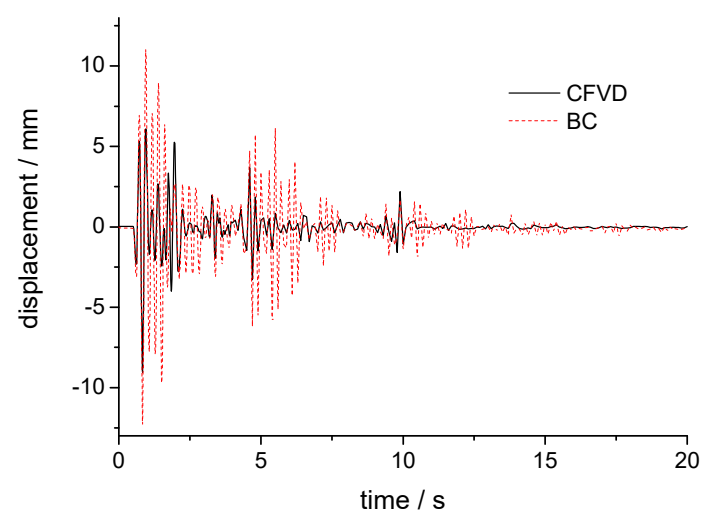

Figure 17. Relative displacement time history curve between side pier and girder of the CFVD system.

Table 5. Comparison of seismic responses of two systems.

\begin{tabular}{cccc}
\hline Item & $\begin{array}{c}\text { Value1 (CHDR } \\
\text { System) }\end{array}$ & $\begin{array}{c}\text { Value2 (CFVD } \\
\text { System) }\end{array}$ & $\begin{array}{c}\text { (Value1 - } \\
\text { Value2)/Value1 }\end{array}$ \\
\hline $\begin{array}{c}\text { Relative displacement between the } \\
\text { side pier and the girder (mm) }\end{array}$ & 10 & 9.1 & $9 \%$ \\
$\begin{array}{c}\text { Peak bending moment at the bottom } \\
\text { of middle pier (kN.m) }\end{array}$ & 38.4 & 38.1 & $1 \%$ \\
$\begin{array}{c}\text { Peak shear force at the bottom of } \\
\text { middle pier(kN) }\end{array}$ & 179.6 & 176.8 & $2 \%$ \\
\hline
\end{tabular}

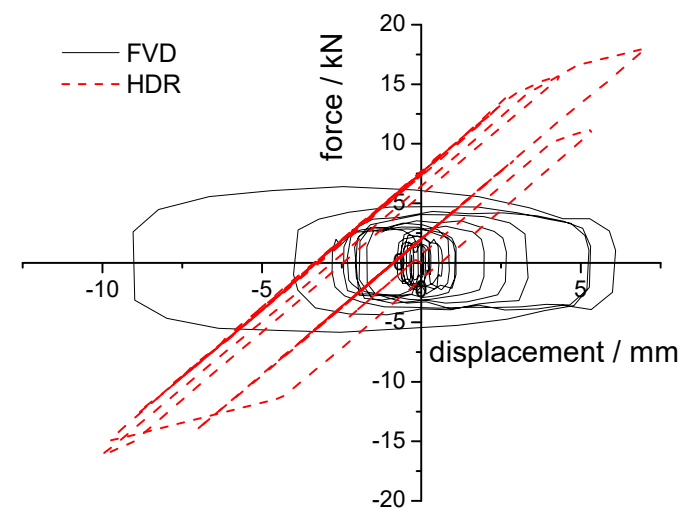

Figure 18. Comparison of hysteretic curves between the FVD and HDR.

\section{(2) Collapse Control effect}

The maximum damping force $F_{\max }$ and the maximum stroke $D_{\max }$ of the FVD are determined to be $10 \mathrm{kN}$ and $\pm 190 \mathrm{~mm}$ respectively by trial calculation, which ensures that the output force and displacement of the dampers do not exceed the capacity range before the bridge collapse.

Under the longitudinal action of the El Centro seismic wave, the CDVD system finally collapsed when the PGA reached $1.4 \mathrm{~g}$, as shown in Figure 19. The specific process is as follows: when $t$ was $0.82 \mathrm{~s}$, the damage begins to appear at the bottom of the middle pier; when $t$ was $0.83 \mathrm{~s}$, the middle bearings failed and the main girder began to slide; when $t$ was $0.85 \mathrm{~s}$, the longitudinal displacement response of the top of the middle pier reached $9.7 \mathrm{~mm}$ (see Figure 20a), resulting in the leakage of tendons at the bottom of the middle pier; when $t$ was $0.86 \mathrm{~s}$, the damage position of the bottom of the middle pier extended upward; when $t$ was $0.9 \mathrm{~s}$, the damage of the main girder resulted in the redistribution of the stress of the girder and the damage of the bottom of the girder near the middle pier; when $t$ 
was $1 \mathrm{~s}$, the longitudinal displacement of the pier top reached $9 \mathrm{~cm}$ under the action of earthquake, the bottom of the middle pier had been completely destroyed, and the vertical displacement reaches 12 $\mathrm{cm}$ (see Figure 20b). Therefore, it could be concluded that the middle pier collapsed. The bottom of the girder near the original middle fulcrum of the main beam lost the support of the substructure, thus the bending cracking was serious, and the bridge deck function was lost, so the bridge specimen collapsed as a whole.

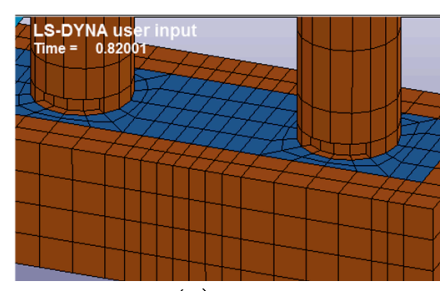

(a) $\mathrm{t}=0.82 \mathrm{~s}$

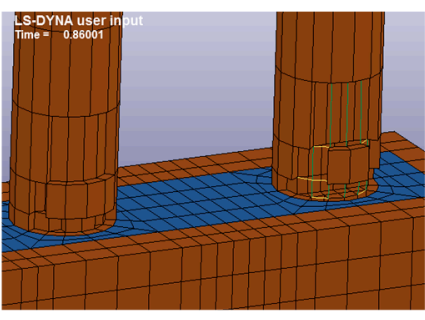

(c) $\mathrm{t}=0.86 \mathrm{~s}$

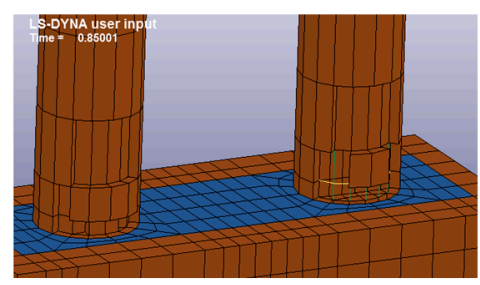

(b) $t=0.85 \mathrm{~s}$

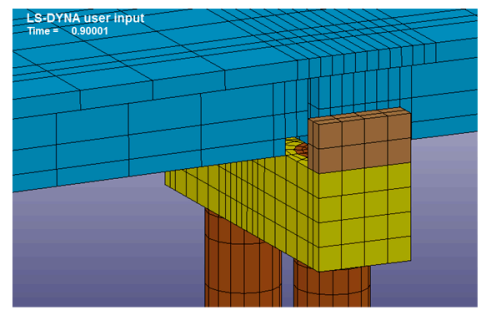

(d) $\mathrm{t}=0.9 \mathrm{~s}$

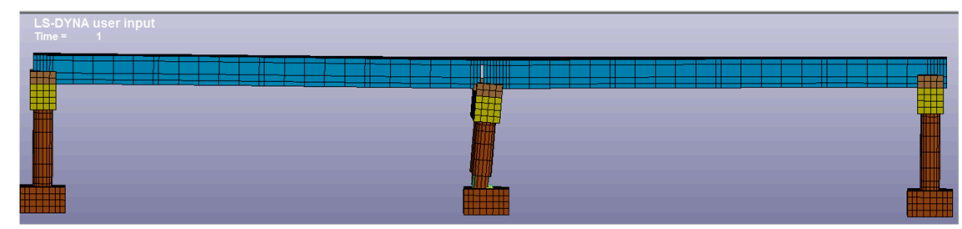

(e) $\mathrm{t}=1 \mathrm{~s}$

Figure 19. Longitudinal collapse mode of the CFVD system under the El Centro wave.

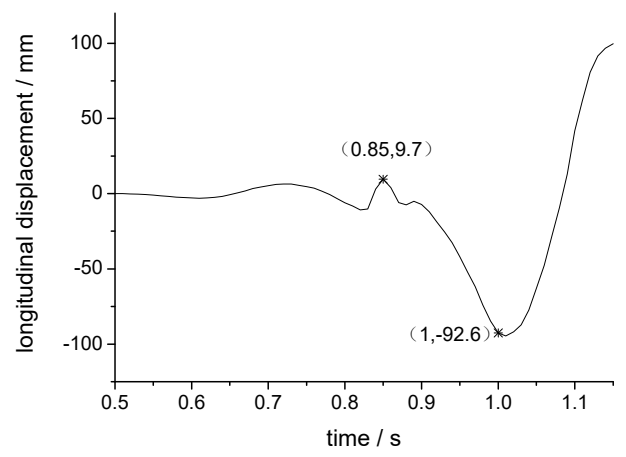

(a)

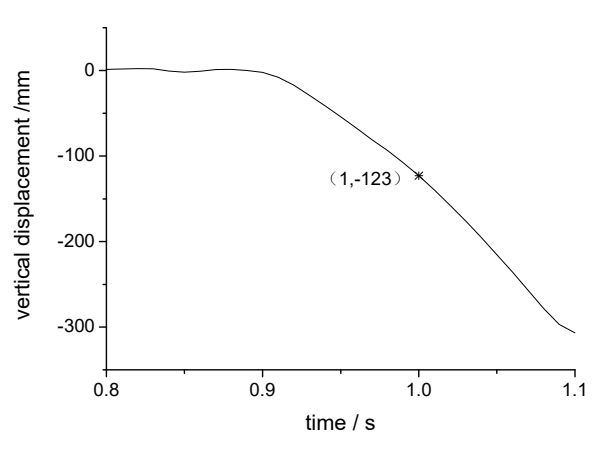

(b)

Figure 20. Displacement time history curve of the top middle pier: (a) longitudinal; (b) vertical.

The bridge specimen of the CFVD system would collapse if the Chi-chi seismic wave input longitudinally with a PGA of $2.8 \mathrm{~g}$, as shown in Figure 21 The specific process is as follows: when $t$ was $12.7 \mathrm{~s}$, the bottom of the middle pier was damaged; when $t$ was $14.04 \mathrm{~s}$, damage of the bottom of the middle pier reached the bare steel bar; when $t$ was $18.1 \mathrm{~s}$, the bottom of the side pier was damaged; when $t$ was $19.96 \mathrm{~s}$, the bottom of the middle pier was seriously damaged, and tendons were exposed at the bottom of the side piers which bearings began to slide; when $t$ was $19.98 \mathrm{~s}$, the longitudinal displacement of the top of the middle pier reached $3.3 \mathrm{~cm}$ (see Figure 12a) and the bottom of the middle pier was completely invalid; when $t$ was $20.06 \mathrm{~s}$, the middle pier fell, the main girder was bent down and the bottom of the beam was damaged; when $t$ was $20.92 \mathrm{~s}$, the main beam was separated from the 
side pier on the left and the dampers had also withdrawn from work; when $t$ was $21.04 \mathrm{~s}$, the main beam was only supported by the side pier on the right, with longitudinal relative displacement of the side pier and the beam of $67 \mathrm{~cm}$, and the main beam was falling to collapse, as shown by Figures $21 \mathrm{f}$ and 22b,c.

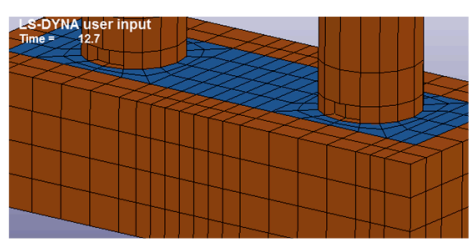

(a) $\mathrm{t}=12.7 \mathrm{~s}$

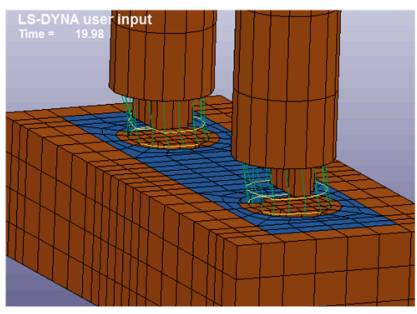

(c) $\mathrm{t}=19.98 \mathrm{~s}$

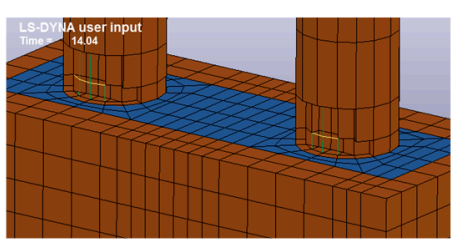

(b) $\mathrm{t}=14.04 \mathrm{~s}$

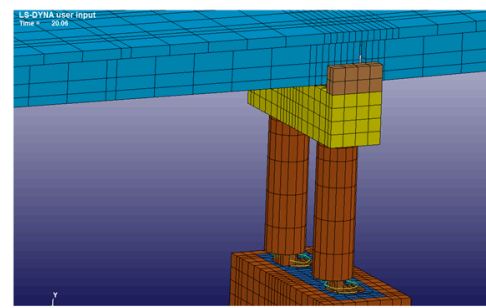

(d) $\mathrm{t}=20.06 \mathrm{~s}$

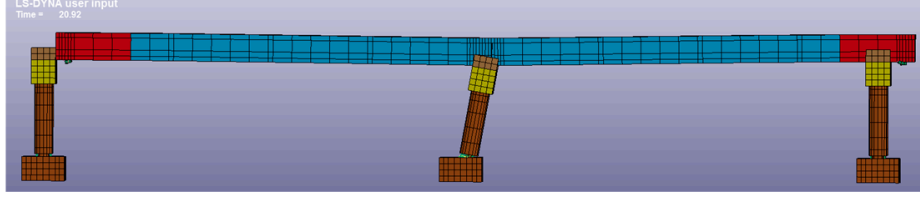

(e) $\mathrm{t}=20.92 \mathrm{~s}$

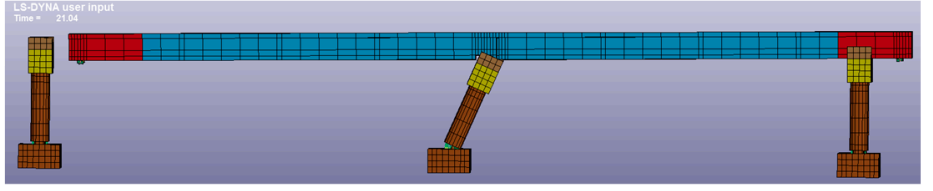

(f) $\mathrm{t}=21.04 \mathrm{~s}$

Figure 21. Longitudinal collapse mode of the CFVD system under the Chi-chi wave.

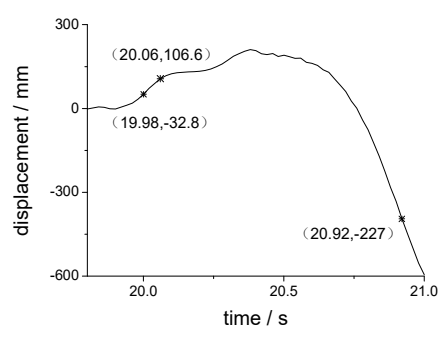

(a)

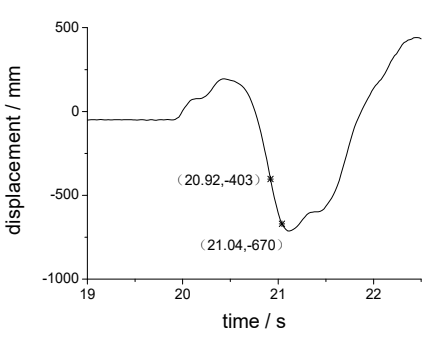

(b)

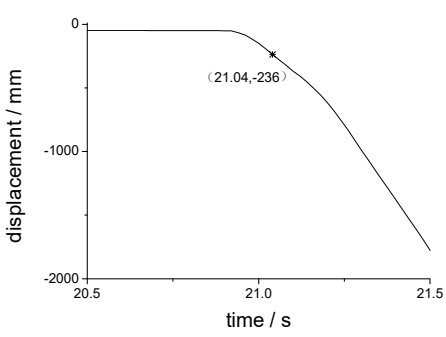

(c)

Figure 22. Displacement time history curve: (a) longitudinal displacement at the top of the middle pier; (b) relative longitudinal displacement of side pier and girder; (c) vertical displacement at the end of the girder.

\subsection{Lock-Up Clutch Control}

\subsubsection{Simulation of Lock-Up Device}

There are four simulation ideas of the lock-up device: first, coupling the degree of freedom between the locked two components [45]; second, treating the locking device as an elastic connection with limited elastic force [46]; third, combining the two ends of the locking device into a rigid node; fourth, treating the locking device as a damper with large damping coefficient [47]. The first three methods can produce large force to realize the instantaneous control of displacement, but they can not reflect the judgment of the condition of velocity locking in Equation (14), and the effects of continuous 
locking force and overestimation of locking force may occur in the simulation. These analysis methods can be used to calculate the structural response safely and are beneficial to the engineering design, so the first three methods are often used to deal with this kind of problem. In this paper, the fourth method will be selected to carefully consider the influence of the lock-up device on the bridge specimen in the process of seismic action. If the lock-up device reaches the control speed $V_{0}$, the maximum locking force $F_{\max }$ will be produced, otherwise, the device will not play any role.

\subsubsection{Analysis of Isolation and Collapse Control Effect of the LUC}

\section{(1) Isolation effect}

The maximum locking force $F_{\max }$ is $10 \mathrm{kN}$, the maximum stroke $D_{\max }$ is $\pm 190 \mathrm{~mm}$, and the control speed $V_{0}$ is $0.02 \mathrm{~m} / \mathrm{s}$, considering results to be comparable to those of other control systems. In order to prove the rationality of the parameter setting, the El Centro wave case with a longitudinal PGA of $0.4 \mathrm{~g}$ was selected for inspection. The peak relative displacement between the side pier and the girder, in this case, was reduced from $12.3 \mathrm{~mm}$ of the BC system to $5.1 \mathrm{~mm}$, which showed an isolation rate of $58.5 \%$, illustrated in Figure 23a. The displacement control of the lock-up clutch scheme was better than that of the HDR isolation scheme or the FVD scheme, which was due to the fact that the locking force output was basically switched between "output" or "non-output" (see Figure 23b), which was very different from that of the FVD. Under the same ground motion, the output of the lock-up clutch of the CLUC system was larger than that of the damper of the CFVD system and directly reached the maximum locking force (see Figure 24). Therefore, the displacement response could be controlled more effectively, but the energy dissipation capacity of the lock-up components was poor, and its output effect was similar to that of rigid members. Thus, the contribution of the lock-up clutch to energy consumption is usually not taken into account.

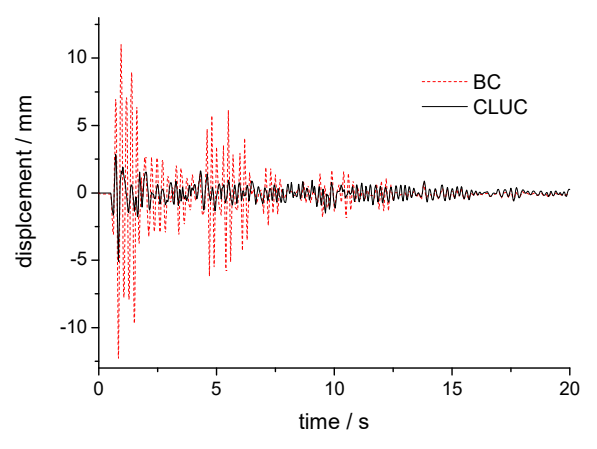

(a)

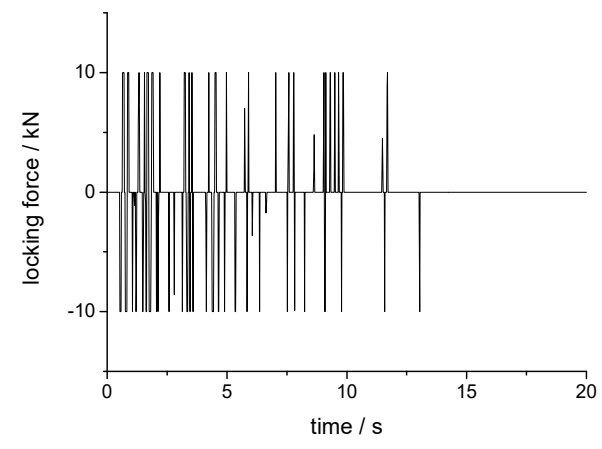

(b)

Figure 23. Time history curve: (a) relative displacement of side pier and girder; (b) output force of lock-up clutch.

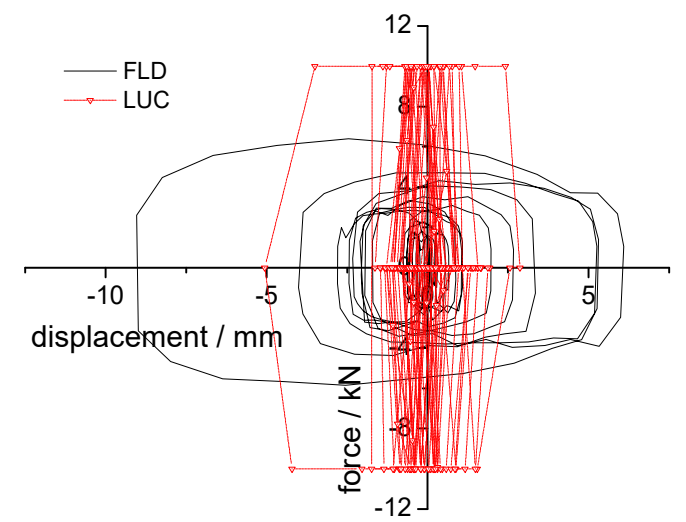

Figure 24. Comparison of the hysteretic curve between the lock-up clutch and the damper. 


\section{(2) Collapse Control effect}

Two typical seismic wave input conditions as mentioned earlier were used to illustrate the collapse characteristics of the CLUC system. Under the action of longitudinal El Centro seismic wave, the bridge model of the CLUC system finally collapsed when the PGA was $1.4 \mathrm{~g}$, as shown in Figure 25. The specific process is as follows: when $t$ was $0.83 \mathrm{~s}$, the middle bearings failed, and the bottom of the middle pier began to be damaged; when $t$ was $0.85 \mathrm{~s}$, tendons were seen at the bottom of the middle pier; when $t$ was $0.93 \mathrm{~s}$, the damage of the bottom of the middle pier was serious and the uncovered tendons were enlarged; when $t$ was $1.06 \mathrm{~s}$, the longitudinal displacement of the top of the middle pier is $3 \mathrm{~cm}$ (see Figure 26a), so the bottom of the pier was completely destroyed, and the damage of the bottom of the main beam was aggravated by the loss of the support of the middle pier; when $t$ was $1.26 \mathrm{~s}$, the middle pier collapsed, and the vertical displacement of the pier top reached $31 \mathrm{~cm}$ (see Figure 26b). The main girder was seriously damaged, so it could be considered that the bridge model collapsed.

Under the action of the longitudinal Chi-chi seismic wave, the bridge specimen of the CLUC system eventually collapsed with a PGA of $1.8 \mathrm{~g}$, as exposed in Figure 27. The specific process was: when $t$ was $16.6 \mathrm{~s}$, the middle pier at the bottom was slightly damaged; when $t$ was $16.86 \mathrm{~s}$, the bottom of middle pier started to leak reinforcement; when $t$ was $17 \mathrm{~s}$, the damage at the bottom of the middle pier was aggravated, and the front and back of the pier column were all leaking bars, thus the damaged part was almost connected into a circle; when $t$ was $17.02 \mathrm{~s}$, the displacement of the top of middle pier was increased to $3.2 \mathrm{~cm}$, and the middle pier failed completely; when $t$ was $18.16 \mathrm{~s}$, bearings on the side pier were sliding; when $t$ was $18.34 \mathrm{~s}$, the locking device failed for it exceeded the maximum stroke of $190 \mathrm{~mm}$; when $t$ was $18.58 \mathrm{~s}$, the main beam moves longitudinally away from the left side pier; when $t$ was $18.78 \mathrm{~s}$, the middle pier was continuously swinging, with peak longitudinal displacement of $43 \mathrm{~cm}$ and peak vertical displacement of $18 \mathrm{~cm}$ (see Figure 28). At this time, the longitudinal spacing of the left side pier and girder was $37 \mathrm{~cm}$ (see Figure 29a), which meant the main beam separated from the left side pier. Therefore, only the right side pier was still supporting the superstructure, resulting in the overall instability of the bridge. It could be seen from Figure $29 \mathrm{~b}$ that the main beam was falling downward continuously. So the bridge specimen of the CLUC system was collapsed.

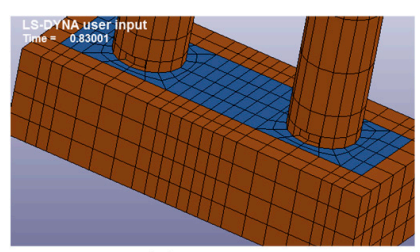

(a) $\mathrm{t}=0.83 \mathrm{~s}$

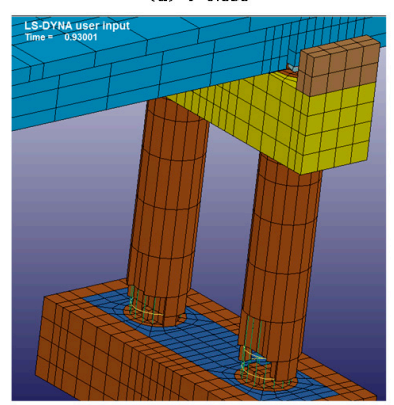

(c) $t=0.93 \mathrm{~s}$

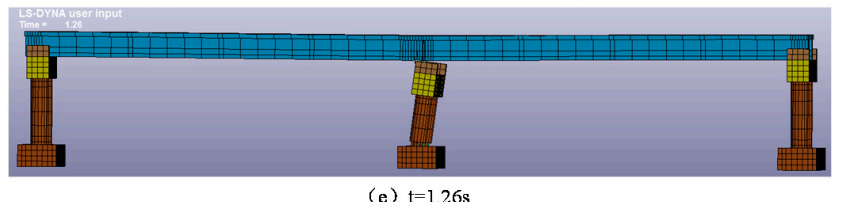

(e) $\mathrm{t}=1.26 \mathrm{~s}$

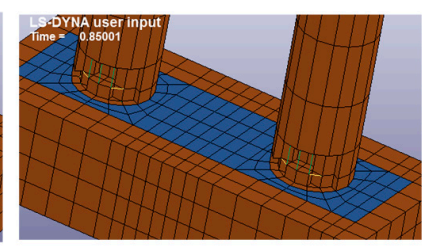

(b) $\mathrm{t}=0.85 \mathrm{~s}$

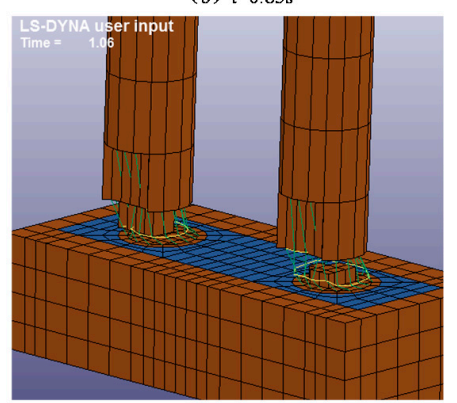

(d) $t=1.06 \mathrm{~s}$

Figure 25. Longitudinal collapse mode of the CLUC system under the El Centro wave. 


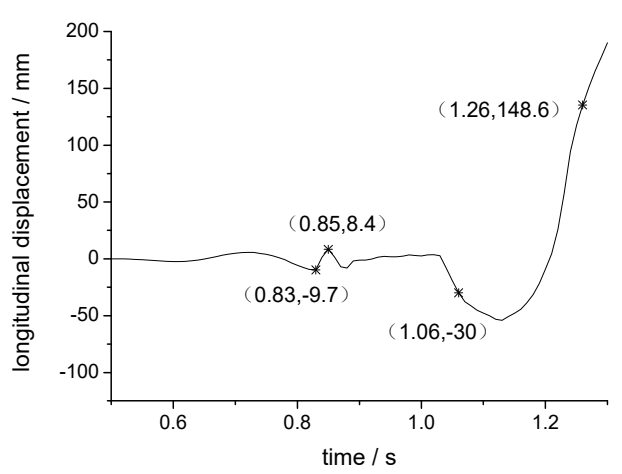

(a)

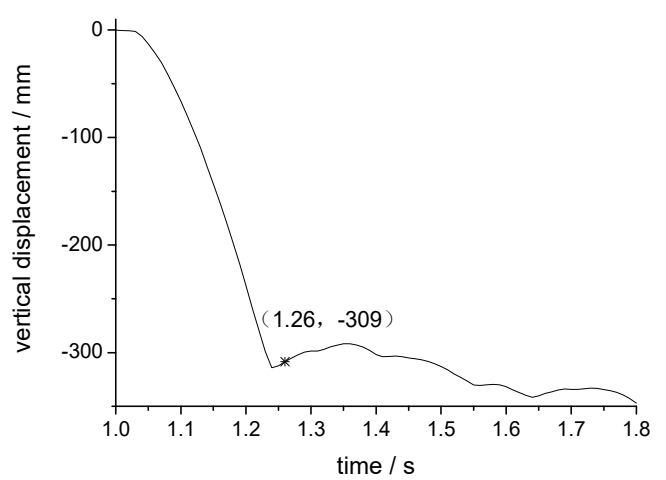

(b)

Figure 26. Time history curve of the top part of the middle pier: (a) longitudinal; (b) vertical.

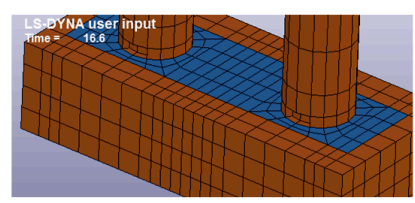

(a) $\mathrm{t}=16.6 \mathrm{~s}$

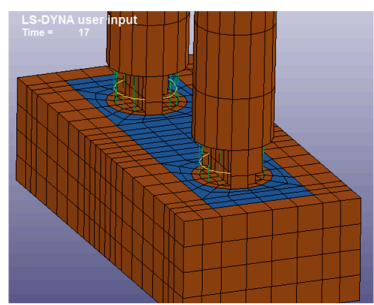

(c) $\mathrm{t}=17 \mathrm{~s}$

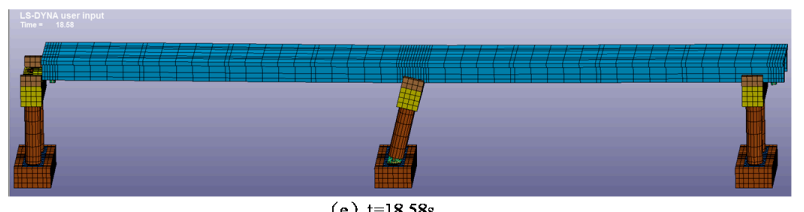

(e) $\mathrm{t}=18.58 \mathrm{~s}$

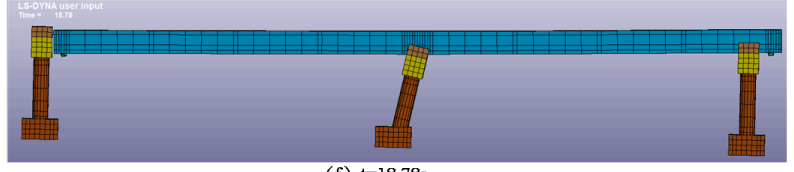

(f) $t=18.78 \mathrm{~s}$

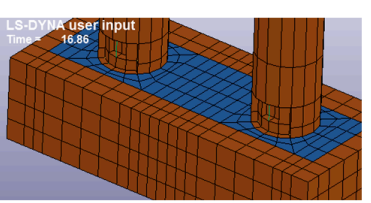

(b) $\mathrm{t}=16.86 \mathrm{~s}$

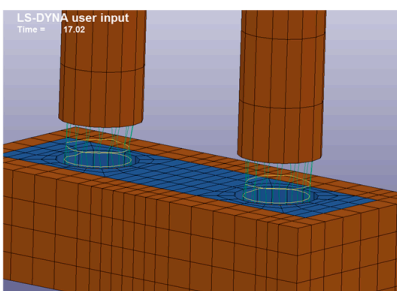

(d) $t=17.02 \mathrm{~s}$

Figure 27. Longitudinal collapse mode of the CLUC system under the Chi-chi wave.

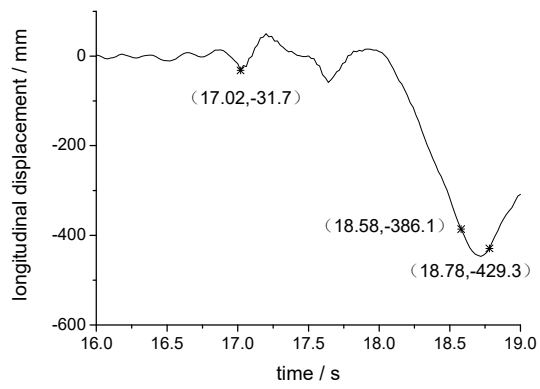

(a)

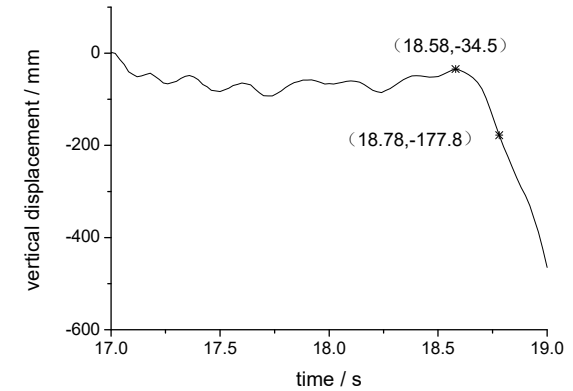

(b)

Figure 28. Time history curve of the top part of the middle pier: (a) longitudinal; (b) vertical. 


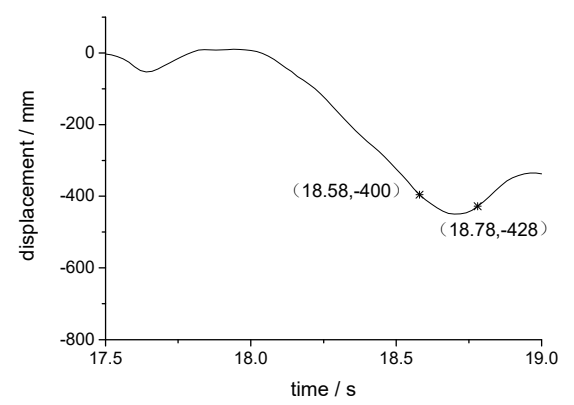

(a)

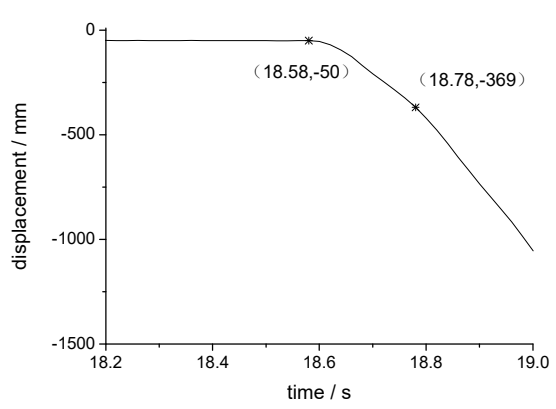

(b)

Figure 29. Time history curve of the CLUC system: (a) relative displacement of side pier and girder; (b) vertical displacement at the end of the main girder.

\subsection{Comparative Analysis of Collapse Control Effect}

It could be seen from the above analysis that the collapse resistance of the bridge specimen could be improved by using three collapse control methods of HDR bearing isolation, FVD damping, and LUC isolation. Although no matter which control method was used, the bridge specimen might still collapse under strong earthquakes, but the target of collapse time backward of the BC system under the strong seismic excitation could be realized by means of various effective control methods. In this paper, the failure of two typical seismic wave input conditions was analyzed, and the collapse characteristics of the bridge specimen after the application of the three control methods are summarized, as shown in Tables 6 and 7.

Table 6. Collapse characteristics of the El Centro seismic wave case.

\begin{tabular}{|c|c|c|c|c|}
\hline $\begin{array}{c}\text { System } \\
\text { Abbreviation }\end{array}$ & BC & CHDR & CFVD & CLUC \\
\hline PGA/g & 1.2 & 2.0 & 1.4 & 1.4 \\
\hline characteristics & $\begin{array}{l}\text { The failure of the middle } \\
\text { pier caused by the } \\
\text { serious damage to the } \\
\text { main beam, which is } \\
\text { V-shaped falling. }\end{array}$ & Like BC & $\begin{array}{l}\text { The failure of the middle } \\
\text { pier caused serious } \\
\text { cracking on the bottom of } \\
\text { the main beam but no } \\
\text { lowering of the girder. }\end{array}$ & Like CFVD \\
\hline
\end{tabular}

Table 7. Collapse characteristics of the Chi-chi seismic wave case.

\begin{tabular}{|c|c|c|c|c|}
\hline $\begin{array}{c}\text { System } \\
\text { Abbreviation }\end{array}$ & BC & CHDR & CFVD & CLUC \\
\hline PGA/g & 1.2 & 1.6 & 2.8 & 1.8 \\
\hline characteristics & $\begin{array}{l}\text { 1. The girder was } \\
\text { damaged. } \\
\text { 2. The side pier on the } \\
\text { right was separated } \\
\text { from the girder to } \\
\text { aggravate the damage } \\
\text { of the girder. } \\
\text { 3. The second span of } \\
\text { the girder fell off. }\end{array}$ & $\begin{array}{l}\text { 1. The relative } \\
\text { displacement of the side } \\
\text { pier and the beam was too } \\
\text { large resulting in the } \\
\text { change of the structural } \\
\text { supporting system. } \\
\text { 2. The main beam was } \\
\text { damaged continuously } \\
\text { and was finally broken } \\
\text { and dropped. }\end{array}$ & $\begin{array}{l}\text { 1. The middle } \\
\text { pier failed. } \\
\text { 2. The main } \\
\text { beam slipped } \\
\text { down from the } \\
\text { side pier on the } \\
\text { left and fell } \\
\text { down. }\end{array}$ & $\begin{array}{l}\text { Like } \\
\text { CFVD }\end{array}$ \\
\hline
\end{tabular}

It can be seen from Table 4 that the damage of the El Centro seismic wave to the bridge specimen is concentrated in the pier column. Because the El Centro seismic wave could excite a strong acceleration response of the cap beam more than the Chi-chi seismic wave, so when the displacement response of the main beam was not significant, the middle pier column has been seriously damaged. HDR bearing 
could reduce the damage degree of the pier and column, but the collapse mode was consistent with the BC system. Due to the displacement control and force sharing of FVD and LUC on the girder, the main beam could still keep seating on the piers after the middle pier failed. Considering the coupling effect of the vertical ground motion and the horizontal ground motion was not taken into account in the above research, it was difficult to ensure that the girder did not fall even if FVD and LUC were used, so it was considered that the bridge specimen had collapsed in the above control conditions.

It can be seen from Table 5 that the HDR bearing played an isolation role on the response of the main beam under the excitation of the Chi-chi seismic wave, but the displacement control effect was not efficient, thus the final collapse mode was similar to that of the BC system, where damage was concentrated on the beam. Both FVD and LUC played a constructive role in displacement control under large displacement and long-period ground motion, which ensured the normal work of the bearing, but it also meant that the inertia force on the substructure would be aggravated with the increase of PGA. Therefore, the ultimate damage mode would be determined by the seismic capacity of the middle pier. Once the middle pier was out of action, the whole structure would soon turn into a maneuvering system and the girder lowered.

\section{Conclusions}

A two-span continuous girder bridge specimen, which had been analyzed by a shaking table test, was discussed in terms of collapse mode and the collapse control strategy. The following conclusions are obtained:

(1) Under the action of longitudinal unidirectional ground motion, two typical collapse modes of the two-span continuous girder bridge with ordinary plate rubber bearing (BC system) were obtained: in $1.2 \mathrm{~g}$ El Centro seismic wave case, the failure of the middle pier caused serious damage of the main girder, which was a V-shaped girder lowering; when the PGA of the Chi-chi seismic wave was $1.2 \mathrm{~g}$, the main beam of the model bridge was damaged and deteriorated due to the separation of the left side pier from the girder, which resulted in the falling of the second span girder.

(2) Three collapse control systems, namely the CHDR control system, CFVD system, and CLUC system, were adopted to explore collapse control effect on the BC system. From the point of view of the shock absorption effect, the CHDR system and the CFVD system were close to each other. Because the hysteretic energy dissipation level of the damper was slightly larger than that of the HDR bearing, the displacement shock absorption effect of the CFVD system is slightly better than that of the CHDR system, but the control effect of the CLUC system on the displacement is the best among them.

(3) Under the action of longitudinal El Centro seismic wave, the CHDR system, CFVD system, and CLUC system collapsed when the PGA was $2.0 \mathrm{~g}$, $1.4 \mathrm{~g}$, and $1.4 \mathrm{~g}$, respectively, while the BC system collapsed when the PGA was $1.2 \mathrm{~g}$. The collapse mode of the CHDR system was the failure of the middle pier resulting in the damage of the main girder which is a V-shaped falling, which was consistent with the BC system. The collapse modes of the CFVD system and CLUC system were similar, which were the failure at the bottom of the middle pier. Because the FVD and LUC control the displacement of the main girder, the falling girder did not occur in the collapse numerical simulation.

(4) Under the action of the longitudinal Chi-chi seismic wave, the CHDR system, CFVD system, and CLUC system collapsed when the PGA was $1.6 \mathrm{~g}, 2.8 \mathrm{~g}$, and $1.8 \mathrm{~g}$, respectively, while the BC system collapsed when the PGA was $1.2 \mathrm{~g}$. The CHDR system reduced the relative displacement between the pier and girder and delayed the time of the girder falling; its collapse mode was consistent with that of the BC system. The displacement control effect of the CFVD system or CLUC system was stronger than that of the CHDR system. The comprehensive displacement control and energy dissipation effect of the FVD was better than that of the LUC. The collapse courses of the CFVD system and CLUC system were similar: first, the earthquake intensity 
increased to cause the middle pier to fail, and then the displacement of the pier and girder was too large to lose the support of one side pier, thus, the bridge became a mobile system, and finally, the girder dropped.

(5) To prevent the failure of this two-span continuous girder bridge under a strong earthquake, it is necessary to select a suitable collapse control device for anti-collapse design. The HDR bearing is suitable for collapse control of bridges built on a slightly rigid field or under medium and short-period ground motion to protect the substructure, in respect for the continuous beam bridge specimen discussed above. When long-period ground motion is input or the site is soft, the FVD or LUC is suitable for collapse control to prevent the beam from falling, and the FVD is preferred if conditions permit.

Author Contributions: The authors contributed equally to this work. Y.L. (Yale Li) analyzed the data and Finished the manuscript writing. Z.Z. provided ideas for this manuscript. B.Y. provided analysis tools. Y.L. (Yuanzheng Lin) managed the analysis data. J.L. graphed the data. All authors have read and agreed to the published version of the manuscript.

Funding: This research was funded by the Construction System Science and Technology Project of Jiangsu Province (grant No. 2019ZD024), and the Open Foundation of Southwest Jiaotong University of Geological Disaster Prevention and Control Technology of Land Transportation (grant No. SWJTU-GGS-2014001).

Conflicts of Interest: The authors declare no conflict of interest regarding the publication of this manuscript.

\section{References}

1. Ledezma, C.; Hutchinson, T.; Ashford, S.A.; Moss, R.; Arduino, P.; Bray, J.D.; Olson, S.; Hashash, Y.M.A.; Verdugo, R.; Frost, D.; et al. Effects of Ground Failure on Bridges, Roads, and Railroads. Earthq. Spectra 2012, 28, 119-143. [CrossRef]

2. Park, R.; Billings, I.J.; Clifton, G.C.; Cousins, J.; Filiatrault, A.; Jennings, D.N.; Jones, L.C.P.; Perrin, N.D.; Rooney, S.L.; Sinclair, J.; et al. The Hyogo-Ken Nanbu earthquake (the Great Hanshin Earthquake) of 17 January 1995. Bull. N. Zealand Soc. Earthq. Eng. 1995, 28, 1-98. [CrossRef]

3. Kawashima, K.; Unjoh, S. The damage of highway bridges in the 1995 hyogo-ken nanbu earthquake and its impact on japanese seismic design. J. Earthq. Eng. 1997, 1, 505-541. [CrossRef]

4. Xue, J.; Lavorato, D.; Bergami, A.; Nuti, C.; Briseghella, B.; Marano, G.C.; Ji, T.; Vanzi, I.; Tarantino, A.M.; Santini, S. Severely Damaged Reinforced Concrete Circular Columns Repaired by Turned Steel Rebar and High-Performance Concrete Jacketing with Steel or Polymer Fibers. Appl. Sci. 2018, 8, 1671. [CrossRef]

5. Lavorato, D.; Bergami, A.V.; Nuti, C.; Briseghella, B.; Xue, J.; Tarantino, A.M.; Santini, S. Ultra-highperformance fibre-reinforced concrete jacket for the repair and the seismic retrofitting of Italian and Chinese RC bridges. In Proceedings of the 6th International Conference on Computational Methods in Structural Dynamics and Earthquake Engineering, Rhodes Island, Greece, 15-17 June 2017; pp. 2149-2160.

6. Lavorato, D.; Nuti, C.; Santini, S. Experimental investigation of the seismic response of repaired r.c. bridges by means of pseudodynamic tests. IABSE Symp. Rep. 2010, 97, 45-52. [CrossRef]

7. Rodrigues, H.; Furtado, A.; Arêde, A.; Vila-Pouca, N.; Varum, H. Experimental study of repaired RC columns subjected to uniaxial and biaxial horizontal loading and variable axial load with longitudinal reinforcement welded steel bars solutions. Eng. Struct. 2018, 155, 371-386. [CrossRef]

8. Rodrigues, H.; Furtado, A.; Arêde, A. Experimental evaluation of energy dissipation and viscous damping of repaired and strengthened RC columns with CFRP jacketing under biaxial load. Eng. Struct. 2017, 145, 162-175. [CrossRef]

9. Han, Q.; Du, X.; Liu, J.; Li, Z.; Li, L.; Zhao, J. Seismic damage of highway bridges during the 2008 Wenchuan earthquake. Earthq. Eng. Eng. Vib. 2009, 8, 263-273. [CrossRef]

10. Schanack, F.; Valdebenito, G.; Alvial, J. Seismic Damage to Bridges during the 27 February 2010 Magnitude 8.8 Chile Earthquake. Earthq. Spectra 2012, 28, 301-315. [CrossRef]

11. Eröz, M.; Desroches, R. Bridge seismic response as a function of the Friction Pendulum System (FPS) modeling assumptions. Eng. Struct. 2008, 30, 3204-3212. [CrossRef]

12. Choi, E.S.; Lee, H.U.; Lee, S.Y. Maintenance and dynamic behavior of advanced spherical bearings under railway open-steel-plate-girder bridges. J. Korean Soc. Railw. 2008, 11, 165-175. 
13. Choun, Y.S.; Choun, Y.-S.; Kim, M.K.; Hahm, D. Revaluation of the aging property modification factor of lead rubber bearings based on accelerated aging tests and finite element analysis. Nucl. Eng. Des. 2019, 347, 59-66. [CrossRef]

14. Okui, Y.; Nakamura, K.; Sato, T.; Imai, T. Seismic response of isolated bridge with high damping rubber bearings. Steel Constr. 2019, 12, 2-9. [CrossRef]

15. Chen, M.C.; Restrepo, J.I.; Benzoni, G. Response of a High Damping Rubber Bearing to Multiaxial Excitation. J. Test. Eval. 2019, 49, JTE20180558. [CrossRef]

16. Constantinou, M.C.; Kartoum, A.; Reinhorn, A.M.; Bradford, P. Sliding Isolation System for Bridges: Experimental Study. Earthq. Spectra 1992, 8, 321-344. [CrossRef]

17. Chen, Y.; Chen, C.; Jiang, H.; Liu, T.; Wan, Z. Study of an innovative graded yield metal damper. J. Constr. Steel Res. 2019, 160, 240-254. [CrossRef]

18. Li, J.; Xiang, N.; Tang, H.; Guan, Z. Shake-table tests and numerical simulation of an innovative isolation system for highway bridges. Soil Dyn. Earthq. Eng. 2016, 86, 55-70. [CrossRef]

19. Xiang, N.; Alam, M.S.; Li, J. Yielding Steel Dampers as Restraining Devices to Control Seismic Sliding of Laminated Rubber Bearings for Highway Bridges: Analytical and Experimental Study. J. Bridg. Eng. 2019, 24, 04019103. [CrossRef]

20. Zhong, J.; Hu, Z.; Yuan, W.; Chen, L. System-based probabilistic optimization of fluid viscous dampers equipped in cable-stayed bridges. Adv. Struct. Eng. 2018, 21, 1815-1825. [CrossRef]

21. Shrestha, B.; Hao, H.; Bi, K. Devices for protecting bridge superstructure from pounding and unseating damages: An overview. Struct. Infrastruct. Eng. 2016, 13, 313-330. [CrossRef]

22. Guo, J.; Zhong, J.; Dang, X.-Z.; Yuan, W.; Alam, M.S. Seismic performance assessment of a curved bridge equipped with a new type spring restrainer. Eng. Struct. 2017, 151, 105-114. [CrossRef]

23. Anderson, D.L.; Mitchell, D.; Tinawi, R.G. Performance of concrete bridges during the Hyogo-ken Nanbu (Kobe) earthquake on January 17, 1995. Can. J. Civ. Eng. 1996, 23, 714-726. [CrossRef]

24. Mylonakis, G.; Syngros, C.; Gazetas, G.; Tazoh, T. The role of soil in the collapse of 18 piers of Hanshin Expressway in the Kobe earthquake. Earthq. Eng. Struct. Dyn. 2006, 35, 547-575. [CrossRef]

25. Hsu, Y.T.; Fu, C.C. Seismic Effect on Highway Bridges in Chi Chi Earthquake. J. Perform. Constr. Facil. 2004, 18, 47-53. [CrossRef]

26. Li, J.; Peng, T.; Xu, Y. Damage investigation of girder bridges under the Wenchuan earthquake and corresponding seismic design recommendations. Earthq. Eng. Eng. Vib. 2008, 7, 337-344. [CrossRef]

27. Hu, M.; Han, Q.; Wen, J.; Bai, Y. Seismic failure of multi-span simply supported RC slab-on-grider bridge in 2008 Wenchuan earthquake: Case study. Eng. Fail. Anal. 2019, 95, 140-153. [CrossRef]

28. Lee, T.-Y.; Hung, W.-H.; Chung, K.-J. Seismic-induced collapse simulation of bridges using simple implicit dynamic analysis. Eng. Struct. 2018, 177, 1-11. [CrossRef]

29. Xie, K.-Z.; Lin, H.-Y.; Yang, S.-S. Collapse-mechanism of Concrete Filled Steel Tube Arch Bridge during strong earthquake. In Proceedings of the 2010 International Conference on Mechanic Automation and Control Engineering, Institute of Electrical and Electronics Engineers (IEEE), Wuhan, China, 3 August 2010; pp. 977-981.

30. Liu, C.; Wang, Y.; Wang, W.; Wu, X. Seismic performance and collapse prevention of concrete-filled thin-walled steel tubular arches. Thin Walled Struct. 2014, 80, 91-102. [CrossRef]

31. Wang, X.; Zhu, B.; Cui, S. Research on Collapse Process of Cable-Stayed Bridges under Strong Seismic Excitations. Shock. Vib. 2017, 2017, 185281. [CrossRef]

32. Yi, J.; Li, J. Longitudinal Seismic Behavior of a Single-Tower Cable-Stayed Bridge Subjected to Near-Field Earthquakes. Shock. Vib. 2017, 2017, 675982. [CrossRef]

33. Das, R.; Pandey, A.; Mahesh, M.; Saini, P.; Anvesh, S. Progressive Collapse of a Cable Stayed Bridge. Procedia Eng. 2016, 144, 132-139. [CrossRef]

34. Kaviani, P.; Zareian, F.; Taciroglu, E. Seismic behavior of reinforced concrete bridges with skew-angled seat-type abutments. Eng. Struct. 2012, 45, 137-150. [CrossRef]

35. Li, Q.; Cheng, M.; Yin, J.; Zhou, C. Study on seismic disaster mechanism of irregular C-shaped curved bridge with high piers. KSCE J. Civ. Eng. 2015, 20, 1429-1436. [CrossRef]

36. Hallquist, J.O. LS-DYNA Theory Manual; Livermore software Technology Corporation: Livermore, CA, USA, 2006; pp. 25-31. 
37. Li, Z.; Zhao, N.; Si, H. The nonlinear finite element analysis of ship hull girder's ultimate strength by explicit algorithm. Ship Sci. Technol. 2015, 37, 11-15. (In Chinese)

38. Shen, X.; Wang, X.; Ye, Q.; Ye, A. Seismic performance of Transverse Steel Damper seismic system for long span bridges. Eng. Struct. 2017, 141, 14-28. [CrossRef]

39. Xu, L.; Cui, Y.; Wang, Z. Active tuned mass damper based vibration control for seismic excited adjacent buildings under actuator saturation. Soil Dyn. Earthq. Eng. 2020, 135, 106181. [CrossRef]

40. Nishi, T.; Murota, N. Elastomeric seismic-protection isolators for buildings and bridges. Chin. J. Polym. Sci. 2012, 31, 50-57. [CrossRef]

41. Li, Y.; Zong, Z.; Yang, B. Experimental Study on Seismic Performance of Concrete Continuous Bridge with HDR Bearings. J. Inst. Eng. Ser. A 2020, 101, 293-314. [CrossRef]

42. Li, Y.; Zong, Z.; Huang, X.; Xia, J.; Liu, L. Experimental study on mechanical properties of high damping rubber bearing model. In Proceedings of the IOP Conference Series: Earth and Environmental Science; IOP Publishing: Bristol, UK, 2017; Volume 61, p. 12105.

43. Li, Y.; Zong, Z.; Liu, S. Shaking table array testing of reinforced concrete continuous girder bridge model. China J. Highw. Transp. 2016, 29, 232-242. (In Chinese)

44. Fragiacomo, M.; Morassi, A. Dynamic testing and parameter identification of a base-isolated bridge. Eng. Struct. 2014, 60, 85-99. [CrossRef]

45. Mao, Y.; Li, J. Analysis of Seismic Mitigation Mechanism and Effect on Longitudinal Direction of Long-span Continuous Bridges. J. Tongji Univ. 2016, 44, 185-191. (In Chinese)

46. Zheng, X.; Fan, Q.; Jin, Y. Analysis of Design and Seismic Isolation Performance of Luck-up Bearing. J. Railw. Eng. Soc. 2015, 32, 73-78. (In Chinese)

47. Xia, X.; Cui, L.; Li, J. Mechanism and analysis model for a lock-up device. J. Harbin Eng. Univ. 2014, 35, 1497-1502. (In Chinese)

(C) 2020 by the authors. Licensee MDPI, Basel, Switzerland. This article is an open access article distributed under the terms and conditions of the Creative Commons Attribution (CC BY) license (http://creativecommons.org/licenses/by/4.0/). 